\title{
Estimation of mineral dust long-wave radiative forcing: sensitivity study to particle properties and application to real cases in the region of Barcelona
}

\author{
M. Sicard ${ }^{1, *}$, S. Bertolín ${ }^{2}$, M. Mallet ${ }^{3}$, P. Dubuisson ${ }^{4}$, and A. Comerón ${ }^{2}$ \\ ${ }^{1}$ RSLab/IEEC-CRAE, Universitat Politècnica de Catalunya, Barcelona, Spain \\ ${ }^{2}$ RSLab, Universitat Politècnica de Catalunya, Barcelona, Spain \\ ${ }^{3}$ Laboratoire d'Aérologie, Université de Toulouse/CNRS, Toulouse, France \\ ${ }^{4}$ Laboratoire d'Optique Atmosphérique, Université Lille 1, Villeneuve d'Ascq, France \\ *on leave at: Laboratoire d'Aérologie, Université de Toulouse/CNRS, Toulouse, France
}

Correspondence to: M. Sicard (msicard@tsc.upc.edu)

Received: 31 January 2014 - Published in Atmos. Chem. Phys. Discuss.: 31 March 2014

Revised: 16 June 2014 - Accepted: 22 July 2014 - Published: 8 September 2014

\begin{abstract}
The aerosol radiative effect in the long-wave (LW) spectral range is sometimes not taken into account in atmospheric aerosol forcing studies at local scale because the LW aerosol effect is assumed to be negligible. At regional and global scale this effect is partially taken into account: aerosol absorption is taken into account but scattering is still neglected. However, aerosols with strong absorbing and scattering properties in the LW region, like mineral dust, can have a non-negligible radiative effect in the LW spectral range (both at surface and top of the atmosphere) which can counteract their cooling effect occurring in the short-wave spectral range. The first objective of this research is to perform a sensitivity study of mineral dust LW radiative forcing (RF) as a function of dust microphysical and optical properties using an accurate radiative transfer model which can compute vertically resolved short-wave and long-wave aerosol RF. Radiative forcing simulations in the LW range have shown an important sensitivity to the following parameters: aerosol load, radius of the coarse mode, refractive index, aerosol vertical distribution, surface temperature and surface albedo. The scattering effect has been estimated to contribute to the LW $\mathrm{RF}$ up to $18 \%$ at the surface and up to $38 \%$ at the top of the atmosphere. The second objective is the estimation of the short-wave and long-wave dust RF for 11 dust outbreaks observed in Barcelona. At the surface, the LW RF varies between +2.8 and $+10.2 \mathrm{~W} \mathrm{~m}^{-2}$, which represents between 11 and $26 \%$ (with opposite sign) of the SW component, while
\end{abstract}

at the top of the atmosphere the LW RF varies between +0.6 and $+5.8 \mathrm{~W} \mathrm{~m}^{-2}$, which represents between 6 and $26 \%$ (with opposite sign) of the SW component.

\section{Introduction}

Atmospheric aerosols have a remarkable effect on the earth's atmosphere radiative budget (Foster et al., 2007). Indeed, aerosols and their interactions with clouds contribute to the largest uncertainties in the estimation of the Earth's changing energy budget (IPCC, 2013). Nowadays many radiative transfer models (RTMs) have been developed to locally estimate the aerosol direct radiative forcing (RF) (Ricchiazzi et al., 1998; Key et al., 1998; Mayer et al., 2005; Berk et al., 2006). Some recent studies focused only in the estimation of the short-wave (SW) RF arguing that the contribution of the long-wave (LW) component was negligible (Roger et al., 2006; Mallet et al., 2008; Sicard et al., 2012). Until 10 years ago few studies considered the LW range due to the difficulties in parameterizing accurately the RTM and the lack of knowledge of the aerosol radiative properties in the LW range (Fouquart et al., 1987; Sokolik and Golitsyn, 1993; Sokolik et al., 1993, 1998; Liao and Seinfeld, 1998; Claquin et al., 1998; Dufresne et al., 2002; Markowicz et al., 2003; Vogelmann et al., 2003). With the initiatives of the AMMA (African Monsoon Multidisciplinary Analysis), 
SAMUM (Saharan Mineral Dust Experiment) and GERBILS (Geostationary Earth Radiation Budget Intercomparisons of Long-Wave and Short-Wave radiation) field campaigns, among others, a series of more recent works on dust microphysical properties and radiative effects in the LW range is available (Otto et al., 2007; 2011; Chou et al., 2008; Hansell et al., 2010; Haywood et al., 2011; Köhler et al., 2011; Osborne et al., 2011; Weinzierl et al., 2011; and papers cited therein).

It is true that the RF of most aerosol types (especially for fine particles such as pollution and smoke) in the LW range is small compared to their forcing in the short wave. However large, highly absorbing and scattering particles such as mineral dust (MD) have been revealed as having a significant forcing in the LW (Fouquart et al., 1987; Dufresne et al., 2002; Hansell et al., 2010; di Sarra et al., 2011). Mineral dust is an atmospheric aerosol present all around the world although it is originated only in a few delimited sources. In Europe the nearest source is the Sahara desert, which is the largest one, emitting half of the world atmospheric MD (Prospero et al., 2002). During its transport, MD properties are modified in such a manner that only a medium-size distribution remains: very large particles (with a diameter $>10 \mu \mathrm{m}$ ) are deposited through wet and dry deposition mechanisms during atmospheric transport (Maring et al., 2003; Ryder et al., 2013a; Osada et al., 2014). In addition to dust particles, sea salt is also a type of particle that could potentially have a significant forcing in the LW range due to its large size and absorbing properties in the $\mathrm{LW}$ region ( $\mathrm{Li}$ et al., 2008). Although confined to the bottom of the planetary boundary layer, sea salt particles can contribute to reduce the top of the atmosphere forcing in the LW spectral range (Markowicz et al., 2003). The radiative impact of sea salt alone is difficult to evaluate in urban areas such as Barcelona where it is mixed with local, urban aerosols. Mostly for this reason sea salt is discarded from our study which concentrates on MD particles only. To characterize the properties of the "typical" MD transported to our region, a climatology data set is proposed.

In this study we start with a rather complete review of the existing knowledge of the MD microphysical and optical properties in the LW spectral range and establish a climatology characterizing the properties of the "typical" transported MD observed in our region. We examine first the sensitivity of LW RF to aerosol physical (particle size, fine/coarse mode ratio) and geometrical properties (aerosol optical depth, layer height) and then the LW scattering effect. The latter process is generally neglected in regional and global climate models (Yu et al., 2006; Yoshioka et al., 2007; Lau et al., 2009; Zhao et al., 2011). This sensitivity study is conducted using the state-of-the-art radiative transfer model GAME (Dubuisson et al., 1996). Also, we identify real situations with high dust loads observed in Barcelona and estimate LW clear-sky direct radiative forcings using combined lidar, sun-photometer and satellite observations. SW clear-sky direct radiative forcings are also estimated to quantify the $\mathrm{LW} / \mathrm{SW}$ forcing ratio.

\section{Mineral dust model in Barcelona}

Among the broad literature available on atmospheric aerosol microphysical and optical properties, many works deal with the characterization of MD particles, though in the LW spectral range, the available literature reduces significantly. MD particles are well characterized by remote sensing observations (Kaufman et al., 2002; Dubovik et al., 2002; Remer et al., 2008; Tanré et al., 2011) and laboratory experiments (Volz, 1972; 1973; 1983), or a combination of both (d'Almeida et al., 1991; Krekov, 1993; Hess et al., 1998). In order to find a model of MD particles representative of long-range transported particles over Barcelona, a climatology of sun-photometer-derived products is established. Some parameters such as the particle shape, the refractive index, the particle density and the vertical distribution are defined through references.

Yang et al. (2007) showed that the nonsphericity effect of dust particles is significant at short wavelengths but not at the thermal infrared wavelengths. More recently, Otto et al. (2011) estimated that the particle non-sphericity had an effect up to $10 \%$ on the LW RF for mineral dust particles observed during SAMUM-1 over Morocco. However, the MD particles observed in Barcelona are smaller than those observed in Morocco and have therefore more regular shapes according to Chou et al. (2008). We can reasonably assume that the MD particle non-sphericity effect on the LW RF in Barcelona is lower than $10 \%$. For that reason particles are assumed to be spherical and the classical Mie theory is employed to compute their optical properties used as input in the GAME RTM. A practical advantage of using a Mie code is that it requires much less computing time than models that compute non-spherical aerosol optical properties (Otto et al., 2009).

\subsection{Refractive index}

Contrary to the short-wave range, the spectral variations in the refractive index in the LW are strong and result in significant changes in the optical coefficients such as the extinction coefficient or the single-scattering albedo. This implies that the variations of the refractive index with wavelength have to be known.

The behaviour of the real and the imaginary part of the refractive index of MD particles as a function of wavelength in the LW has been reported for the first time in a limited number of studies performed more than two decades ago (Volz, 1972, 1973, 1983; Fouquart et al., 1987). The refractive index of MD particles as a function of wavelength in the LW has also been treated later in reference books about atmospheric aerosols such as by d'Almeida et al. (1991) and 

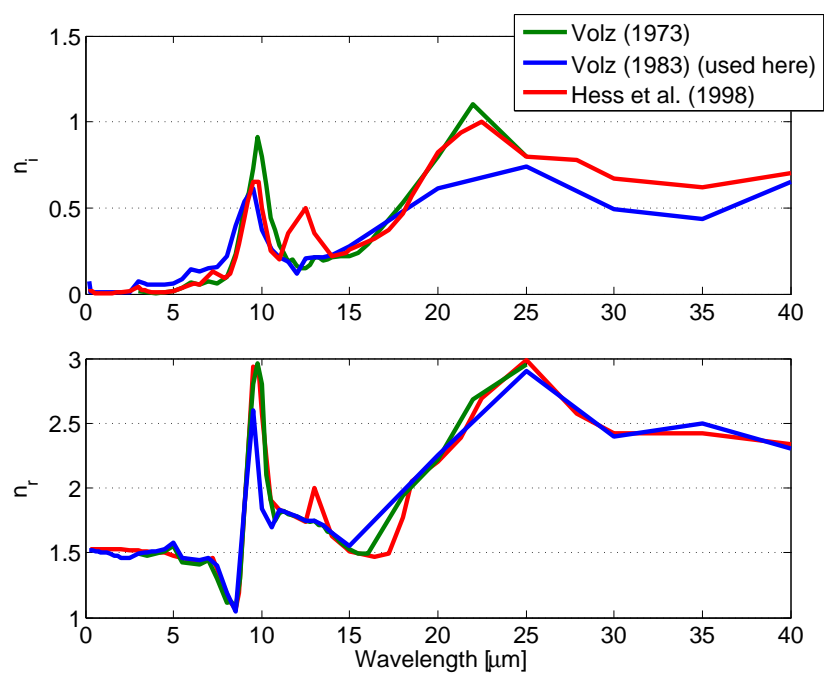

Figure 1. Mineral dust spectral dependency of the (bottom) real part, $n_{\mathrm{r}}$, and (top) imaginary part, $n_{\mathrm{i}}$, of the refractive index from different literature sources.

Krekov (1993), and in the software package OPAC (Optical Properties of Aerosols and Clouds) (Hess et al., 1998). There, the authors have compiled previous studies and have come up with "corrected" refractive indices.

The values of the refractive index considered here come from measurements taken in Meppen in western Germany (Volz, 1983). The table giving the refractive index as a function of the wavelength was found in Krekov (1993). MD particles, including soot, one of the main drivers of the absorption, were obtained after removal of water solubles and of particles with radii greater than $1.5 \mu \mathrm{m}$ (Volz, 1983). Figure 1 shows the variation of the MD refractive index as a function of wavelength from 0.2 to $40 \mu \mathrm{m}$. For comparison, indices from Volz (1973) and Hess et al. (1998) are also reported. The figure shows large spectral variations in the infrared atmospheric window $(8-13 \mu \mathrm{m})$, which have an important impact on the infrared radiative budget of the atmosphere. The real parts of the refractive index, $n_{\mathrm{r}}$, are nearly equal in the entire spectral range. The imaginary part, $n_{\mathrm{i}}$, of Volz (1983) differs from the two others in two regions. It is lower above $18 \mu \mathrm{m}$. However, this difference in $n_{\mathrm{i}}$ will have a negligible impact on the radiative forcing calculations as the radiative forcing at wavelengths greater than $15 \mu \mathrm{m}$ is close to zero (see Sect. 4). In the 3 to $8 \mu \mathrm{m}$ range the imaginary part of Volz (1983) is clearly above the others, by a value of $\sim 0.05$. The most probable reason for that difference is the MD origin: Volz (1973) and Hess et al. (1998) do not refer directly to transported MD. For example, the refractive index in Hess et al. (1998) is dominantly from d'Almeida et al. (1991) who defines a dust-like aerosol by measuring soil dust obtained by evaporation of rain and snow water (Volz, 1972), without referring directly to MD. Finally, the refractive index of Volz (1983) is also in good agreement with more recent studies such as by Otto et al. (2007) who calculated a mean real and imaginary part extracted from a wide range of the literature data by applying a moving average, emphasizing the large variability of the dust refractive index in the literature. To a lesser extent the measurements from McConnell et al. (2010) are, on average, also in agreement with the refractive index chosen in this study at least between 6 and $10 \mu \mathrm{m}$ (no data are shown above $10 \mu \mathrm{m}$ in McConnell et al., 2010).

At this point it is important to recall that our analysis is based on the assumption that pure dust is present, besides the fact that during its transport from the source to the Barcelona region, MD might mix with different aerosol types and at different attitude levels (although it remains the dominant aerosol in the atmospheric column). In those cases the refractive index changes and consequently modifies the aerosol optical properties and the radiative budget (Gómez-Amo et al., 2010). Such cases have been discarded as far as possible by applying restrictive criteria in the MD discrimination method (see next section).

\subsection{Size distribution, concentration and aerosol optical depth}

The MD size distribution and concentration have been retrieved by long-term AERONET (Aerosol Robotic Network; Holben et al., 1998) sun-photometer measurements in Barcelona during the period 23 December 2004-15 September 2012. Only level-2 data have been considered. In the above-mentioned period a total of 4529 size distribution inversions are available.

MD aerosol size distributions are assumed to be lognormal. MD particles have been discriminated by applying the method described in Gobbi et al. (2007) and Basart et al. (2009) that classifies the aerosols as MD when the Ångström exponent, $\mathrm{AE}_{440,870}$, is less than 0.75 , and the difference $\delta \mathrm{AE}=\mathrm{AE}_{440,675}-\mathrm{AE}_{675,870}$ is less than 0.3 . $\mathrm{AE}_{\lambda_{1}, \lambda_{2}}$ refers to the Ångström exponent calculated between the two wavelengths $\lambda_{1}$ and $\lambda_{2}$. To guarantee errors less than $30 \%$, Gobbi et al. (2007) recommend applying an additional criterion on the aerosol optical depth (AOD) at $675 \mathrm{~nm}$ : $\mathrm{AOD}>0.15$. The distribution of all points with $\mathrm{AOD}>0.15$ at $675 \mathrm{~nm}$ is shown in Fig. 2 in a so-called $\delta \mathrm{AE}$ versus $\mathrm{AE}$ plot. The measurements representatives of MD particles according to the discrimination described above fall inside the red rectangle: there are a total of 134 measurements, distributed over 54 days. The average size distribution of those 134 measurements, represented in Fig. 3, shows the strong predominance of the coarse mode, as expected. Incidentally, it is very similar in shape and magnitude to the size distribution of a MD event with AODs at $500 \mathrm{~nm}$ of $\sim 0.38$ and described as typical MD aerosol conditions in southwestern Spain (Cachorro et al., 2008). The mean values of the fine and coarse volume median radii, $r_{\mathrm{V}, \mathrm{f}}$ and $r_{\mathrm{V}, \mathrm{c}}$, their associated standard deviations, $\sigma_{\mathrm{V}, \mathrm{f}}$ and $\sigma_{\mathrm{V}, \mathrm{c}}$, their volume concentrations, $C_{\mathrm{V}, \mathrm{f}}$ and $C_{\mathrm{V}, \mathrm{c}}$, respectively, and the total AOD 
Table 1. Characteristics of the MD model. Each value in the table is accompanied by a standard deviation. $r_{\mathrm{V}}$ and $\sigma_{\mathrm{V}}$ are the volume median radius and standard deviation, $C_{\mathrm{V}}$ the volume concentration and $r_{\mathrm{g}}$ and $N$ the median radius and number concentration.

\begin{tabular}{lll}
\hline & Fine mode & Coarse mode \\
\hline Refractive index & \multicolumn{2}{c}{ Volz (1983); blue curve in Fig. 1 } \\
$r \mathrm{~V}[\mu \mathrm{m}]\left(r_{\mathrm{g}}[\mu \mathrm{m}]\right) ; \sigma \mathrm{V}$ & $0.146 \pm 0.023(0.057 \pm 0.013) ; 0.56 \pm 0.06$ & $2.001 \pm 0.297(0.649 \pm 0.099) ; 0.61 \pm 0.06$ \\
$C_{\mathrm{V}}\left[\mu \mathrm{m}^{3} \mu \mathrm{m}^{-2}\right]\left(N\left[\mathrm{~cm}^{-3}\right]\right)$ & $0.036 \pm 0.018(13.728 \pm 8.647)$ & $0.176 \pm 0.074(0.029 \pm 0.010)$ \\
AOD at $500 \mathrm{~nm}$ & & $0.37 \pm 0.13$ \\
\hline
\end{tabular}

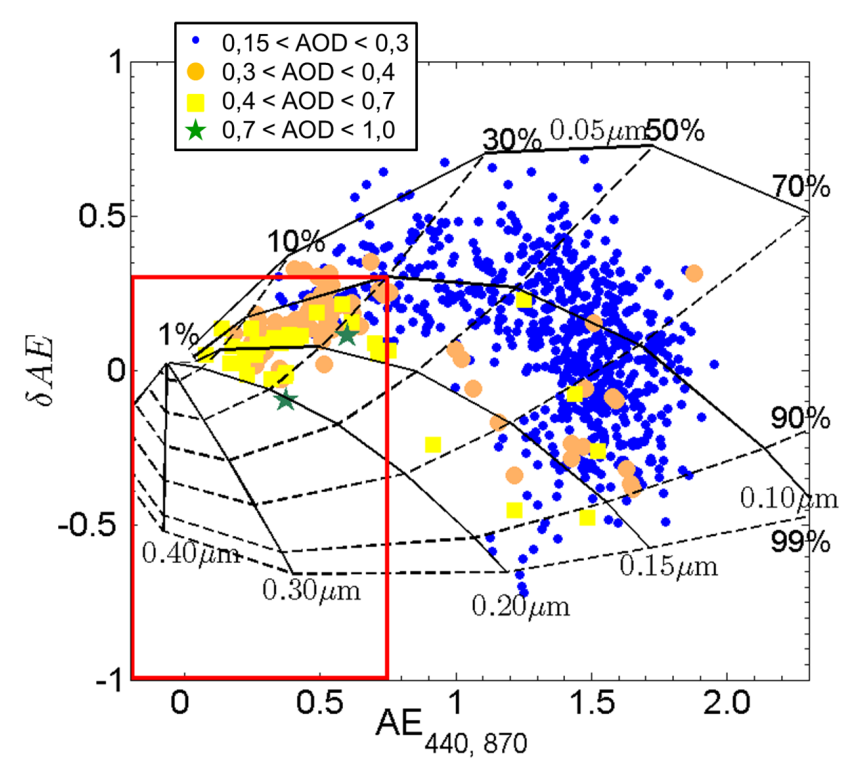

Figure 2. AERONET measurements in Barcelona in a $\delta \mathrm{AE}$ versus AE plot diagram. The Ångström difference is defined as $\delta \mathrm{AE}=\mathrm{AE}_{440,675}-\mathrm{AE}_{675,870}$. Lines are computed for $n_{\mathrm{r}}=1.4$ and $n_{\mathrm{i}}=0.001$. The black solid lines are each for a fixed fine-mode radius, $r_{\mathrm{g}, \mathrm{f}}$, and the dashed black lines for a fixed fraction of the finemode contribution to the AOD at $675 \mathrm{~nm}$.

at $500 \mathrm{~nm}$ are reported in Table 1. All those magnitudes are products from the AERONET inversion code (Dubovik and King, 2000; Dubovik et al., 2000). Because of the longrange transport of the MD between the source and the region of Barcelona, the coarse-mode radius and volume concentration ratio found here $\left(r_{\mathrm{V}, \mathrm{c}}=2.001 \mu \mathrm{m}\right.$ and $C_{\mathrm{V}, \mathrm{c}} / C_{\mathrm{V}, \mathrm{f}} \sim$ 5) are lower than those measured near the MD source in Bahrain, Persian Gulf ( $r_{\mathrm{V}, \mathrm{c}}=2.540 \mu \mathrm{m}$ and $\left.C_{\mathrm{V}, \mathrm{c}} / C_{\mathrm{V}, \mathrm{f}} \sim 10\right)$ and in Solar Village, Saudi Arabia $\left(r_{\mathrm{V}, \mathrm{c}}=2.320 \mu \mathrm{m}\right.$ and $\left.C_{\mathrm{V}, \mathrm{c}} / C_{\mathrm{V}, \mathrm{f}} \sim 50\right)$ (Dubovik et al., 2002), which are representative of so-called pure desert dust. The mean total AOD at $500 \mathrm{~nm}$ is $0.37 \pm 0.13$. Because of the influence of MD this value is much larger than the mean summer AOD of 0.20 (at $532 \mathrm{~nm}$ ) measured in Barcelona (Sicard et al., 2011). Several authors have commented on the discrepancies of size distributions of large particles (with a diameter $>10 \mu \mathrm{m}$ ) observed between AERONET and in situ measurements near the source (Reid et al., 2003; McConnell et al., 2008; Otto et

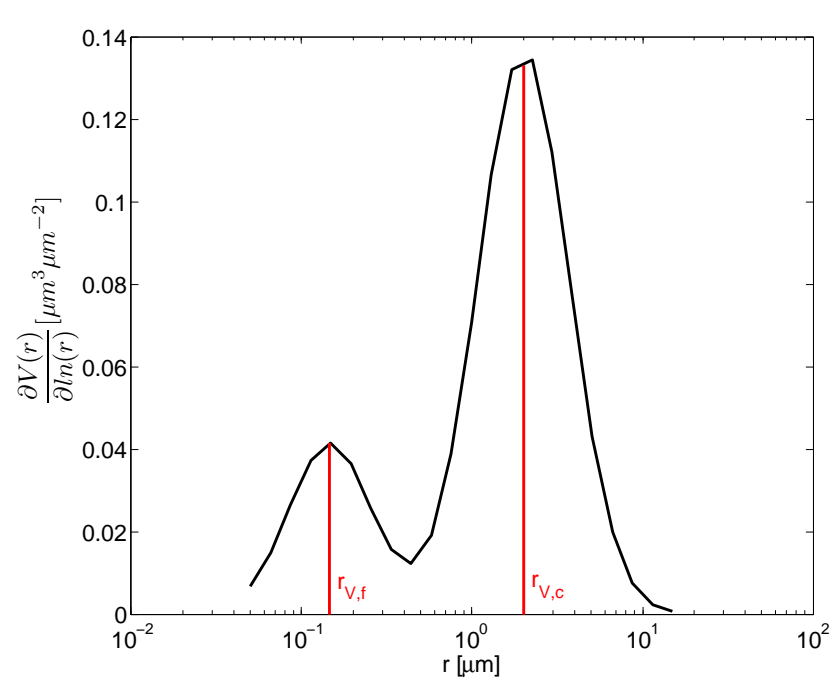

Figure 3. Size distribution of the MD model. It has been calculated as the average of the 134 AERONET size distribution retrievals in Barcelona identified as MD particles in the period 23 December 2004 to 15 September 2012. More information is available in Table 1 .

al., 2009; 2011; Müller et al., 2010, 2012). One finds among the explanations of those discrepancies: measurement technique inaccuracy (cut-off problem, e.g. AERONET inversion algorithm retrieves particles with radii between 0.05 and $15 \mu \mathrm{m})$, horizontally and vertically non-homogeneous atmosphere, the mineralogical constitution of the dust ensemble, the uncertainty in the complex refractive index and the nonsphericity of the particles. In the present work the MD arrives in Barcelona after several days of long-range transport and it is very unlikely that large particles (with a diameter $>10 \mu \mathrm{m}$ ) remain in the atmosphere (Maring et al., 2003; Ryder et al., 2013a; Osada et al., 2014).

The input of our Mie code is the median (equivalent to the geometric mean) radius, $r_{\mathrm{g}}$, and the standard deviation, $\sigma_{\mathrm{g}}$, of the lognormal distribution, as well as the particle number, $N$. Those parameters are given in Table 1 . The conversion of AERONET volumetric products to those parameters is given in the Appendix. 


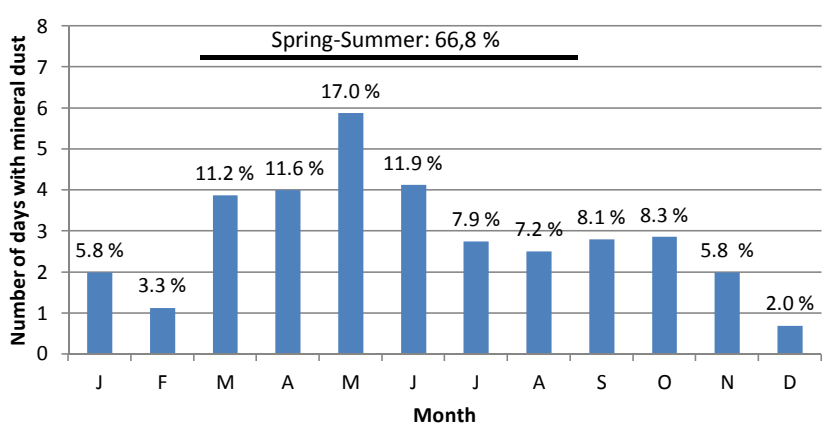

Figure 4. Number of days per month with MD from AERONET measurements in Barcelona. The numbers above the bars indicate their frequency with respect to the total annual number of days with MD. The number of days with MD in spring and summer represent $66.8 \%$ of the total annual number of days with MD.

\subsection{Mineral dust model in Barcelona}

The climatology established in Sect. 2.2 allows for the determination of the most representative model of MD observed in our region. In order to determine how the MD events are distributed over the year in Barcelona, we represent in Fig. 4 the number of days per month of MD observed by the AERONET sun-photometer. The discrimination method from Gobbi et al. (2007) has been used on all the AOD retrievals from AERONET in the period 23 December 2004 to 15 September 2012. 270 days were found, which, over the whole period, represents $9.6 \%$ of the time. This value is lower than the $17 \%$ of African dust frequency in the region of Barcelona referenced by Pey et al. (2013) based on surface $\mathrm{PM}_{10}$ measurements. The main reason is that in a large number of cases the MD is embedded in clouds, so that, by using only level 2 AERONET data, those cases have been discarded here. Anyway, a close correspondence between $\mathrm{PM}_{10}$ and columnar MD detected from the AOD spectral dependency is not expected since transport processes over the Mediterranean Sea frequently force the MD layers to travel above the marine boundary layer and not into it, especially in summer (Marconi et al., 2014). Two thirds of the events occur during the spring-summer period, while almost $40 \%$ occur during the spring period alone. A peak of about 6 days/month in May appears clearly above the others. Those results are in relatively good agreement with Pey et al. (2013), in which the contribution of MD has been estimated monthly from 10 years of ground-based measurements of $\mathrm{PM}_{10}$ in several areas across the Mediterranean Basin, in spite of the differences between the two approaches: we refer here to the total columnar amount of MD, while Pey et al. (2013) refers to the amount of MD at ground level.

The extinction coefficient, $\alpha$, normalized to that at $500 \mathrm{~nm}$, the scattering albedo, $\omega_{0}$, and the asymmetry factor, $g$, are calculated using a Mie code in a tunable range of 115 wavelengths. The size distribution is integrated between radius of
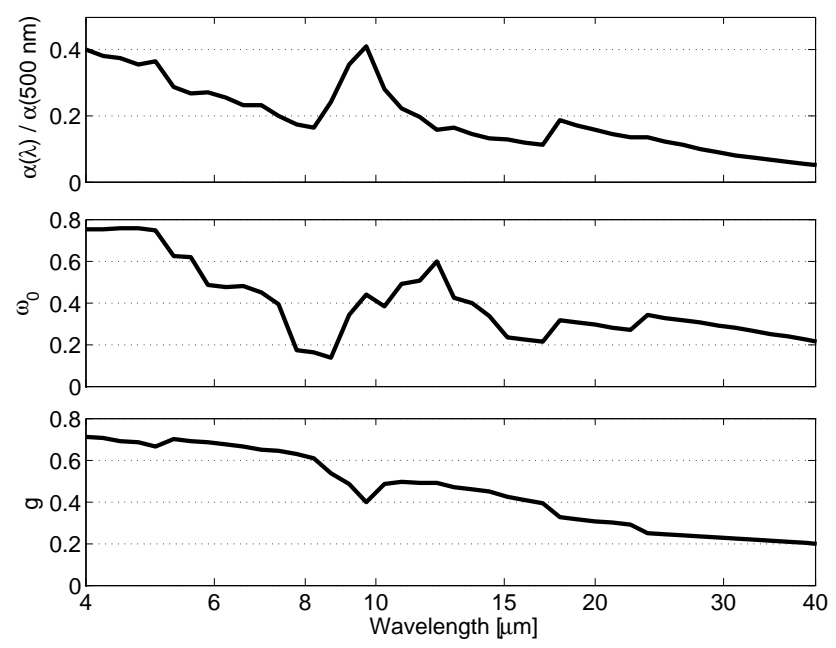

Figure 5. Wavelength dependence of the optical properties of the bimodal distribution of MD defined in Table 1. Top: extinction coefficient normalized at $500 \mathrm{~nm}$; centre: single-scattering albedo; bottom: asymmetry factor.

0.001 up to $25 \mu \mathrm{m}$ (except for Fig. 7c and d). The spectral behaviour of all three parameters is shown in Fig. 5. The MD particle density has been taken as $2.6 \mathrm{~g} \mathrm{~cm}^{-3}$ (Hess et al., 1998). Those three optical parameters have a general tendency to decrease with wavelength: at $4 \mu \mathrm{m}$ the particles are moderately absorbing $\left(\omega_{0} \sim 0.8\right)$ and their scattering rather forward $(g \sim 0.7)$; at $40 \mu \mathrm{m}$ the particles are highly absorbing $\left(\omega_{0} \sim 0.2\right)$ and their scattering rather isotropic $(g \sim 0.2)$. In the range $8-15 \mu \mathrm{m}$ strong spectral variations are observed.

\section{Radiative transfer model}

Irradiances in the long-wave spectral region have been calculated using a fast yet accurate RTM, referred to as the GAME code (Dubuisson et al., 2004; 2006). GAME allows one to calculate upward and downward fluxes, $F$, at the bottom (BOA) and at the top (TOA) of the atmosphere in the infrared spectral range $(4-50 \mu \mathrm{m})$. For this study 40 vertical levels have been used between ground and $100 \mathrm{~km}$ height with a resolution of $1 \mathrm{~km}$ from the surface to $25 \mathrm{~km}, 2.5 \mathrm{~km}$ between 25 to $50 \mathrm{~km}, 5 \mathrm{~km}$ at 55 and $60 \mathrm{~km}$ and $20 \mathrm{~km}$ at 80 and $100 \mathrm{~km}$. Aerosol forcing has been calculated as

$$
\begin{aligned}
& \Delta F_{\mathrm{BOA}}=\left(F_{\mathrm{BOA}}^{\mathrm{w}} \downarrow-F_{\mathrm{BOA}}^{\mathrm{w}} \uparrow\right)-\left(F_{\mathrm{BOA}}^{\mathrm{o}} \downarrow-F_{\mathrm{BOA}}^{\mathrm{o}} \uparrow\right) \\
& \text { and } \\
& \Delta F_{\mathrm{TOA}}=\left(F_{\mathrm{TOA}}^{\mathrm{w}} \downarrow-F_{\mathrm{TOA}}^{\mathrm{w}} \uparrow\right)-\left(F_{\mathrm{TOA}}^{\mathrm{o}} \downarrow-F_{\mathrm{TOA}}^{\mathrm{o}} \uparrow\right) \\
& =-\left(F_{\mathrm{TOA}}^{\mathrm{w}} \uparrow-F_{\mathrm{TOA}}^{\mathrm{o}} \uparrow\right),
\end{aligned}
$$

where $F^{\mathrm{w}}$ and $F^{\mathrm{o}}$ are the radiative fluxes with and without aerosols, respectively. The $\downarrow$ and $\uparrow$ arrows indicate whether the fluxes are downward or upward, respectively. The simplification of Eq. (2) implies the assumption that the amount 
of the incoming solar radiation at the TOA is equal for both cases with and without aerosols. With this convention, a negative sign of $\Delta F$ implies an aerosol cooling effect independently of whether it occurs at the BOA or at the TOA. In Sect. 5, the SW spectral component is also estimated to quantify the LW/SW forcing ratio. Both the SW and LW spectral components have been treated separately. A description of the model in the SW spectral region $(0.2-4 \mu \mathrm{m})$ can be found in Roger et al. (2006), Mallet et al. (2008) and Sicard et al. (2012).

\subsection{Model description in the $L W$ spectral range}

GAME accounts for thermal emission, absorption and scattering, as well as their interactions, using the Discrete Ordinates Method (DISORT) (Stamnes et al., 1988). This accurate method makes it possible to calculate solar and thermal infrared fluxes (from 0.2 to $50 \mu \mathrm{m}$ ) at any atmospheric level with the assumption of a vertically inhomogeneous media, stratified into plane and homogeneous layers. In addition, the GAME code has a fixed spectral resolution $\left(\Delta v=20 \mathrm{~cm}^{-1}\right)$ over the whole infrared spectral range.

Gaseous absorption $\left(\mathrm{H}_{2} \mathrm{O}, \mathrm{CO}_{2}, \mathrm{O}_{3}, \mathrm{~N}_{2} \mathrm{O}, \mathrm{CO}, \mathrm{CH}_{4}\right.$ and $\mathrm{N}_{2}$ ) is treated from the correlated $k$ distribution (Lacis and Oinas, 1991). Considering a layer at pressure $P$ and temperature $T$, the transmission function for a spectral interval $\Delta v$ is approximated by an exponential summation over a limited number $N$ of absorption classes as

$T_{\Delta v}(P, T)=\sum_{i=1}^{N} a_{\mathrm{i}} \exp \left[-k_{\mathrm{i}}(P, T) u(P, T)\right]$,

with $u$ the absorber amount. The weight $a_{\mathrm{i}}$ represents the probability associated to the mean absorption coefficient $k_{\mathrm{i}}$ for each absorption class $i$. The coefficients of the exponential series $\left(a_{\mathrm{i}}\right.$ and $\left.k_{\mathrm{i}}\right)$ have been determined with reference calculations from a line-by-line (LBL) code (Dubuisson et al., 1996, 2005), using the spectroscopic database HITRAN (Rothman et al., 2009). The coefficients $a_{\mathrm{i}}$ and $k_{\mathrm{i}}$ are then calculated for a set of reference pressure $P$ and temperature $T$ with the LBLDOM (LBL Discrete Ordinates Method) code (Dubuisson et al., 1996). The $k$-distribution coefficients are available upon request to the authors. For a given atmospheric profile, these coefficients are calculated using interpolations. Note that the correlated $k$-distribution technique makes it possible to account for interaction between gaseous absorption and multiple scattering with manageable computational time. In addition, the impact of the absorption continua is modelled using the CKD (Clough, Kneizys and Davis) formulation (Clough et al., 1989).

One of the main specificities of the GAME code in the LW range is the complete representation of the LW aerosol scattering which is most of the time neglected in regional and global climate models in spite of its effect on the LW RF (Yu et al., 2006; Yoshioka et al., 2007; Lau et al., 2009;
Zhao et al., 2011). Indeed, Dufresne et al. (2002) have shown that the TOA LW RF could be increased by about $50 \%$ when this process is taken into account. The scattering effect is included in the sensitivity study proposed in this work, but the study has been refined with respect to Dufresne et al. (2002) to be more representative of long-range transported MD: Dufresne et al. (2002) used an AOD of 1 at $500 \mathrm{~nm}$ which is much higher than the mean AOD of 0.37 of our MD model. The spectral optical properties of aerosols are defined for each atmospheric layer where dust is present, including the moments of the phase function, the single-scattering albedo and the extinction optical depth (the total columnar AOD is assumed to be distributed vertically homogeneously within the dust layer). The moderate spectral resolution of GAME makes it possible to account for the spectral variations of aerosol properties, especially in the infrared window.

\subsection{Model parameterization}

Besides aerosol optical properties, the RTM is sensitive to atmospheric parameters such as the relative humidity and the air temperature profiles, the surface emissivity and temperature or the aerosol vertical distribution. Some other parameters (e.g. the sun position) are involved in the calculation but are not commented on here, because they have a negligible effect on the LW RF.

\subsubsection{Atmospheric profiles}

In a first approximation the RTM model was run with a midlatitude summer (MLS) profile taken from the US Standard Atmosphere, 1976 model (McClatchey et al., 1972). In order to check how the model compares to real atmospheric profiles, we use the results from Sicard et al. (2013) in which the MLS profiles are compared to the seasonal mean profiles of temperature, pressure and relative humidity measured by radiosoundings launched every day in Barcelona between June 2008 and February 2013 at 12:00 UT. The mean profiles of the joined spring and summer seasons have also been calculated, as the spring and summer seasons represent together two thirds of the MD frequency in Barcelona (see Sect. 2.3). In general the MLS model overestimates the values of temperature and relative humidity at all heights and for all seasons, while the profiles of pressure are all similar. Similarities were found between the MLS and the summer temperature profiles and between the MLS and the autumn relative humidity profiles. Those similarities have a direct impact on the LW RF also given in Sicard et al. (2013) as a function of wavelength: the MLS and the summer profiles give very similar RF at the BOA, while the best agreement at the TOA is obtained for the autumn season. The largest difference between the MLS and the spring-summer period occurs at the TOA and nearly reaches $30 \%$. Because the MLS and the spring-summer profiles give quite different RF, the latter are used in the sensitivity study. 
Table 2. Generic parameters for the sensitivity study. The parameters from CERES are accompanied by a standard deviation.

\begin{tabular}{lll}
\hline & Value & Source \\
\hline Atmospheric profiles & Fig. 4 in Sicard et al. (2013) & \\
Surface albedo & $0.017 \pm 0.001$ & CERES spring-summer \\
Surface temperature & $297.49 \pm 7 \mathrm{~K}$ & CERES spring-summer \\
Aerosol vertical distribution & $1.5-3.5 \mathrm{~km}$ & Adjusted to model levels after Papayannis et al. (2008) \\
Zenith angle & $0^{\circ}$ & - \\
\hline
\end{tabular}

\subsubsection{Surface properties}

Contrary to the short-wave region, where the albedo (or reflectivity), $\rho$, can be highly directional, in the LW it is possible to approximate the surface as Lambertian. If Earth is considered in thermodynamic equilibrium, the emissivity, $\varepsilon$, is related to the albedo by $\varepsilon=1-\rho$. The surface emissivity has been calculated as the mean of the surface emissivities available in the Single Scanner Footprint (SSF) Level2 products of the CERES (Clouds and the Earth's Radiant Energy System) sensor in the spectral range of its WN "window" $(8.1$ to $11.8 \mu \mathrm{m})$ for the seasons of spring and summer between June 2007 and May 2012. The surface emissivity is computed based on observed CERES scene types, MODIS (Moderate Resolution Imaging Spectroradiometer) imager data and a lookup table of spectral albedo (emissivity) for each scene type. More details can be found at http: //www-surf.larc.nasa.gov/surf/pages/explan.html. The corresponding surface albedo over the Barcelona region is 0.017 . The associated standard deviation is 0.001 , indicating a very low variability of this parameter (its minimum and maximum values are 0.013 and 0.018 , respectively). The value of 0.017 is lower than values of soil albedo based on 58 data sets of ASTER in the same spectral range shown in Otto et al. (2011) and is representative of a mixture of ocean and land. Indeed CERES SSF Level 2 products are given for a spatial resolution equivalent to its instantaneous footprint, 38 by $31 \mathrm{~km}$ at nadir, which covers a large area encompassing the city of Barcelona.

The surface temperature was also calculated as the mean of the surface temperatures available in the SSF Level2 products of CERES for the same seasons of spring and summer. The surface temperature contained in those files is based on the Global Modeling and Assimilation Office (GMAO)'s Goddard Earth Observing System (GEOS). The mean surface temperature over the Barcelona region is $297.49 \mathrm{~K}$ with an associated standard deviation of $7 \mathrm{~K}$ (minimum and maximum values of 279.64 and $318.52 \mathrm{~K}$, respectively). Those values are summarized in Table 2.

\subsubsection{Aerosol stratification}

The aerosol vertical distribution was set to the MD layer characteristics based on observations over a period of 3 years (Papayannis et al., 2008). In Barcelona, the MD layer base mean is $1434 \pm 441 \mathrm{~m}$ and the top mean is $3608 \pm 1605 \mathrm{~m}$. In order to adjust those layers to the vertical levels defined in GAME, the MD vertical distribution in Barcelona has been set to $1500-3500 \mathrm{~m}$. Below 1500 and above $3500 \mathrm{~m}$, it is assumed that no aerosol is present. In those layers the extinction coefficient has a mean value of $\sim 70 \mathrm{Mm}^{-1}$ with peaks that can exceed $100 \mathrm{Mm}^{-1}$ (Sicard et al., 2011).

\section{Sensitivity study in the long-wave spectral range}

The MD model parameters and the generic parameters of the sensitivity study are given in Tables 1 and 2, respectively. Figures 6 and 7 show the LW RF as a function of different parameters. The sensitivity study is motivated by the effect of large particles on the LW RF through their radiative properties stressed by several authors (Otto et al., 2007, 2009, 2011; McConnell et al., 2008; Ryder et al., 2013b). However, other parameters on which the LW RF is dependent, such as the aerosol load, the coarse/fine mode concentration ratio, the aerosol vertical distribution, the surface temperature and the surface albedo, are also studied.

Figure 6 shows the LW spectral RF as a function of wavelength at the BOA and at the TOA, and for the fine and the coarse mode. Most of the forcing occurs in the atmospheric window of 8 to $13 \mu \mathrm{m}$ where large spectral variations of the refractive index occur (see Sect. 2.1). The spectral forcing at the surface is about twice as high as at the TOA. This is due to the fact that the main source of LW radiation, the Earth, is close to the lowermost aerosol layers. At the TOA, the overall effect of aerosols is to reduce the upward long-wave radiation emitted by the surface through absorption and scattering. At the TOA large particles have also a non-negligible effect on the spectral RF in the 17 to $22 \mu \mathrm{m}$ range. At both the BOA and the TOA the effect of small particles represents approximately $10 \%$ of the LW spectral RF.

The LW RF at the BOA and the TOA as a function of AOD at $500 \mathrm{~nm}$ is shown in Fig. $7 \mathrm{a}$. As the height of the MD layer $(1.5-3.5 \mathrm{~km})$ is relatively close to the surface where the main source of LW radiation is, the MD layer produces a LW RF at the surface higher than at the TOA.

Figure $7 \mathrm{~b}$ shows the behaviour of the RF as a function of the MD layer height, assuming a MD layer thickness of $1 \mathrm{~km}$. Aerosols scatter, absorb and re-emit radiation in all directions. A temperature effect on the forcing at the surface is 

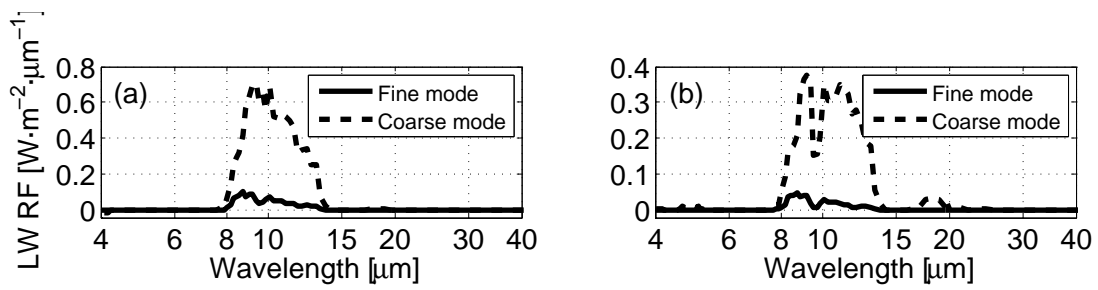

Figure 6. Long-wave spectral radiative forcing as a function of wavelength at (a) the BOA and (b) the TOA for the fine and coarse mode.
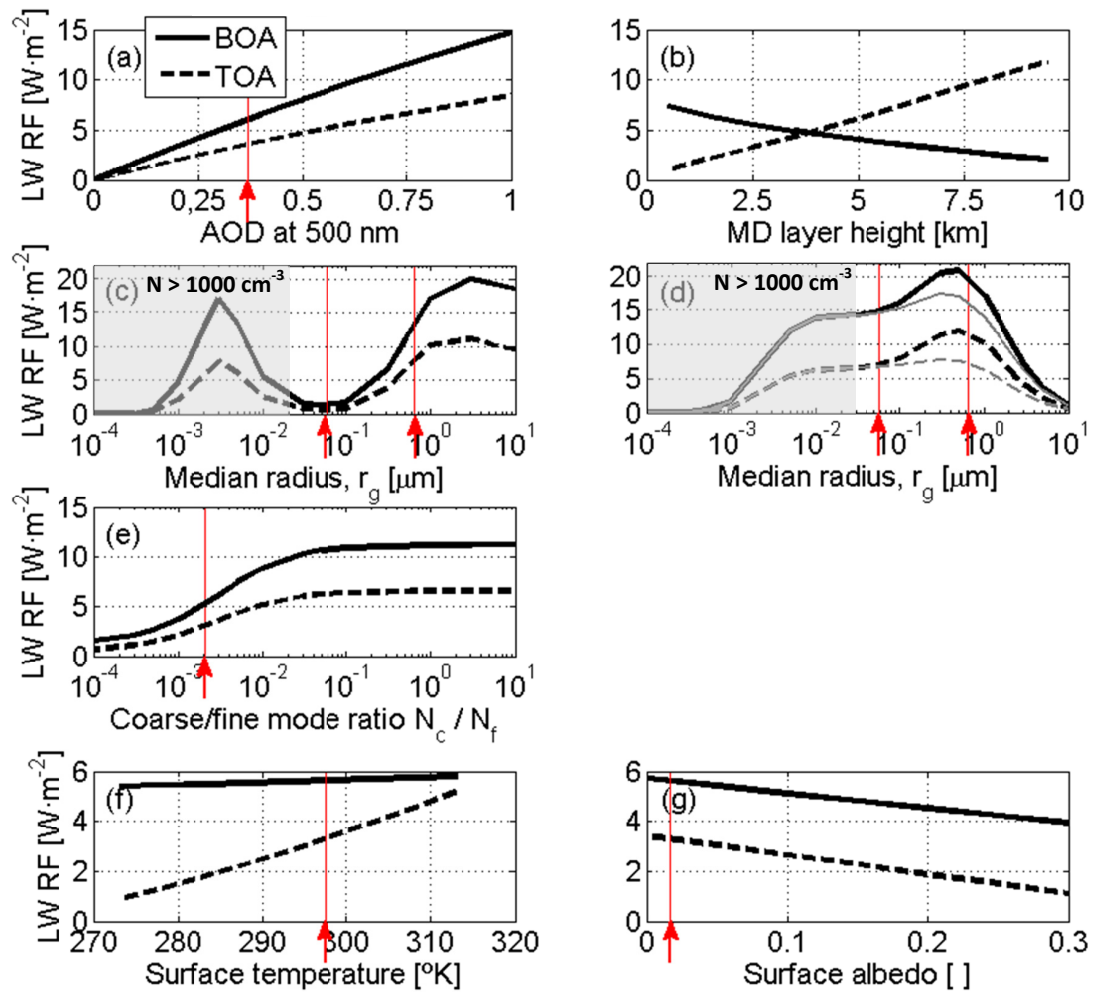

Figure 7. LW RF as a function of (a) AOD at $500 \mathrm{~nm}$, (b) MD layer height assuming a $1 \mathrm{~km}$ thickness, (c) particle median radius maintaining and (d) maintaining the volume constant, (e) coarse/fine-mode ratio, (f) surface temperature and (g) surface albedo. The legend in (a) is the same for all the plots. In (d), the lines in grey represent the RF without considering the aerosol scattering properties. The red arrows indicate the values taken for the MD model.

clearly visible: the lower the aerosol layer, the higher its temperature, and therefore the higher its absorption. This effect is well reproduced in Fig. 7b where the LW RF at the BOA is high near the surface and decreases with increasing height while at the TOA it behaves oppositely. It is believed that the forcing at the TOA is driven by scattering since in our MD model the scattering occurs preferably in the forward direction ( $g \approx 0.5$ in the 8 to $13 \mu \mathrm{m}$ range, Fig. 5).

Figure $7 \mathrm{c}$ shows the particle size dependency of the LW $\mathrm{RF}$ for a constant AOD of 0.37 at $500 \mathrm{~nm}$. The size distribution is assumed to be monomodal and the AOD is maintained constant by adjusting the particle number, $N$. To maintain the AOD constant for small particles, it is necessary to increase the particle number to unrealistically large values.
For $r_{\mathrm{g}}<0.02 \mu \mathrm{m} N$ has to be larger than $\sim 1000 \mathrm{~cm}^{-3}$. This value of $N$ was measured by Wagner et al. (2009) inside a dust plume with an AOD of $\sim 0.4$ at $440 \mathrm{~nm}$ (higher than the AOD of 0.37 at $500 \mathrm{~nm}$ of our MD model) for submicron particles. Thus we set this value of $N$ as the upper limit beyond which Fig. 7c stops from having a physical meaning. In the figure the region in which $N$ exceeds that limit, and therefore the curves lose their physical meaning, is marked by a semi-transparent, grey rectangle and is not discussed in the following. Between 0.02 and $0.5 \mu \mathrm{m}$ in radius and in the LW spectral range the absorption coefficient decreases and the single-scattering albedo increases from nearly zero. From $0.5 \mu \mathrm{m}$, the absorption as well as the scattering increase, hence the increase in the RF seen in Fig. 7c. We note 
that the LW RF of the MD model $\left(+6.02 \mathrm{~W} \mathrm{~m}^{-2}\right.$ at the BOA and $+3.58 \mathrm{~W} \mathrm{~m}^{-2}$ at the TOA, see the RF in Fig. $7 \mathrm{a}$ at the red arrow) falls between the two red arrows indicating the fine and coarse mode of the MD model. The increase of the LW $\mathrm{RF}$ for radii $>0.1 \mu \mathrm{m}$ up to values of $\sim 20 \mathrm{~W} \mathrm{~m}^{-2}$ at the BOA and $\sim 11 \mathrm{~W} \mathrm{~m}^{-2}$ at the TOA are quantitatively and qualitatively in good agreement with the calculations of LW RF by Otto et al. (2011) for various particle diameter (see the plots over land in Fig. 14 of that reference).

Figure $7 d$ shows the LW RF as a function of the particle size maintaining constant the volume occupied by the particles. The AOD is no longer constant. A monomodal distribution is considered. We depart from particles with a median radius $r_{\mathrm{g}}^{\prime}=1 \mu \mathrm{m}$ and calculate the particle number, $N^{\prime}$, necessary to obtain an AOD of 0.37. For all the values of $r_{\mathrm{g}}$ explored in Fig. $7 \mathrm{~d}$ the product $\left(r_{\mathrm{g}}\right)^{3} \times N$ is maintained constant and equal to $\left(r_{\mathrm{g}}^{\prime}\right)^{3} \times N^{\prime}$. The standard deviation of the size distribution is maintained constant. Here again, it is necessary to increase the particle number to unrealistically large values to maintain the product $\left(r_{\mathrm{g}}\right)^{3} \times N$ constant for small particles: the limit of $N=1000 \mathrm{~cm}^{-3}$ is reached for particles with a radius of $0.03 \mu \mathrm{m}$. The semi-transparent, grey rectangle in Fig. 7d represents the region where $N$ exceeds that limit and where the figure is not discussed. We have mathematically checked that maintaining constant the volume occupied by the particles is equivalent to maintaining constant the volume concentration $C_{\mathrm{V}}$. For particles with a radius lower than $0.1 \mu \mathrm{m}$ nearly all the extinction is due to absorption $\left(\omega_{0}=0\right)$, while for greater radius the optical properties are similar to those of Fig. 5. For very large particles $\left(r_{\mathrm{g}}>10 \mu \mathrm{m}\right), \omega_{0} \approx 0.5$ and $N$ is very low. This produces the LW RF to be nearly 0 . In Fig. 7d the LW RF neglecting scattering (grey lines) clearly show that for radii lower than $0.1 \mu \mathrm{m}$ the scattering properties have no effect on the LW RF. For radii greater than $0.1 \mu \mathrm{m}$, the scattering effect contributes to the LW RF up to $18 \%$ at the BOA and up to $38 \%$ at the TOA. The highest contribution is reached for particles with a radius of $0.5 \mu \mathrm{m}$, which is close to the coarse radius of our MD model, $0.649 \mu \mathrm{m}$. This point emphasizes the importance of the scattering effect when studying the LW RF of longrange transported MD.

Figure 7e shows the LW RF dependency on the ratio of coarse to fine mode particle concentration, $N_{\mathrm{c}} / N_{\mathrm{f}}$. One sees that the amount of RF produced by small particles is less than $14 \%$ at the BOA and less than $10 \%$ at the TOA compared to that produced by large particles. Figure $7 \mathrm{e}$ follows the same shape as the single-scattering albedo versus $N_{\mathrm{c}} / N_{\mathrm{f}}$ at $8.5 \mu \mathrm{m}$ for the "Sahara dust-Barbados" aerosol type shown in Sokolik et al. (1998). According to the results from Sokolik et al. (1998) $\left(\omega_{0}\right.$ versus $N_{\mathrm{c}} / N_{\mathrm{f}}$ nearly constant at 11 and $12 \mu \mathrm{m}$, and increasing at $8.5 \mu \mathrm{m}$ ), we conclude that the increase of $\mathrm{RF}$ with increasing $N_{\mathrm{c}} / N_{\mathrm{f}}$ is mostly due to the low values of the single-scattering albedo around the wavelength of $8 \mu \mathrm{m}$ (see Fig. 5).

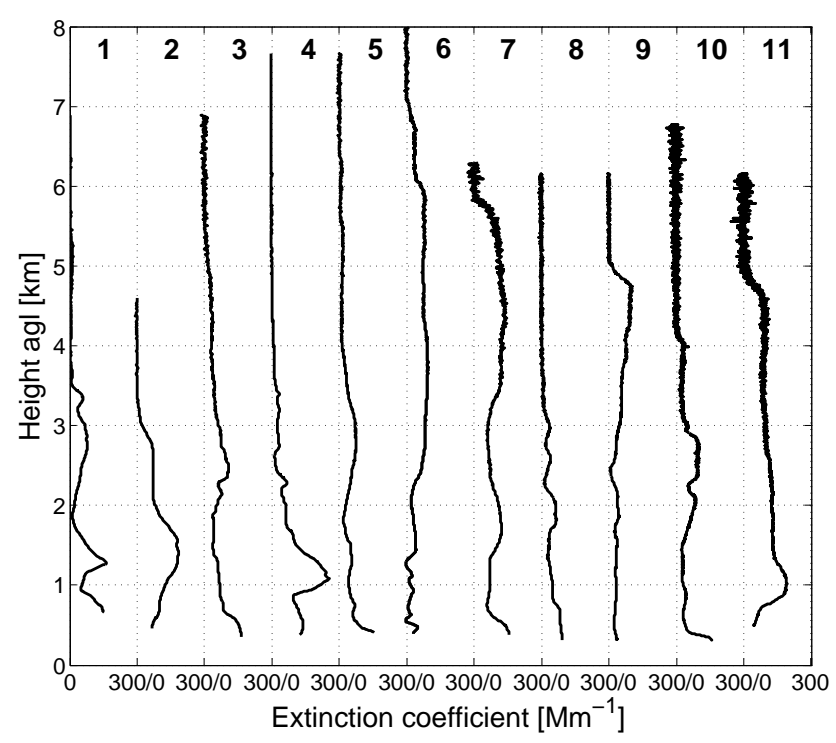

Figure 8. Lidar-derived profiles of the aerosol extinction coefficient for the 11 cases. The case number is indicated below the upper abscissa axis.

Finally, Fig. 7f and g show the LW RF as a function of the surface temperature (in the range $0-40{ }^{\circ} \mathrm{C}$ ) and the surface albedo (in the range $0-0.3$ ), respectively. The range of the surface albedo was chosen according to the results from Wang et al. (2005) in which the spectral emissivity of many kind of ground materials has been estimated and is always larger than 0.7 in the spectral range from 3 to $14 \mu \mathrm{m}$. From Fig. $7 \mathrm{f}$ the LW RF at the TOA is more sensitive to surface temperature change than the LW RF at the surface. This figure illustrates well the works from Dufresne et al. (2002) in which a simple conceptual model formalizes that sensitivity: the LW RF at the TOA is proportional to the absorption and reflection coefficients of the aerosol layer (that multiplies the upward irradiance at the surface which depends directly on the surface temperature) whereas at the BOA it is proportional to the reflection coefficient. Figure $7 \mathrm{~g}$ shows that the LW RF decreases with increasing surface albedo. This result was expected since as the surface albedo increases, its emissivity decreases and therefore less LW radiation reaches the aerosol layer.

\section{Application to real cases over Barcelona}

The RF is estimated for 11 real cases of MD outbreaks in Barcelona which took place between 2007 and 2012. All cases are documented by lidar, sun-photometer, radiosoundings and CERES SSF Level2 products and have been identified as MD outbreaks by applying the method described in Gobbi et al. (2007) (see Sect. 2.2). Both the SW and LW radiative forcings have been calculated with the GAME code and are reported in Table 3. Except cases 7 and 8 which are 
Table 3. Instantaneous radiative forcing (last four columns) estimated for the 11 cases for which the MD layer radiative properties have been calculated. Time refers to the lidar start time (all lidar measurements are of a duration of 30 min). AOD is the AOD measured by the sun-photometer at $500 \mathrm{~nm}$. $\Delta h$ is the overall thickness of the MD layer. SA is the surface albedo calculated from the surface emissivity measured by CERES. ST is the surface temperature measured by CERES. Mn stands for "mean".

\begin{tabular}{lllllllllll}
\hline Case & Day & Time & AOD & $\begin{array}{l}\Delta h \\
{[\mathrm{~km}]}\end{array}$ & SA & $\begin{array}{l}\text { ST } \\
{\left[{ }^{\circ} \mathrm{K}\right]}\end{array}$ & BOA SW & $\begin{array}{l}\text { TOA SW } \\
{\left[\mathrm{W} \mathrm{m}^{-2}\right]}\end{array}$ & $\begin{array}{c}\text { BOA LW } \\
\text { TOA LW }\end{array}$ \\
\hline 1 & $21 / 05 / 2007$ & $16: 11$ & 0.28 & 4.95 & 0.017 & 298.04 & -54.8 & $-15,5$ & $+6,9$ & $+2,1$ \\
2 & $24 / 05 / 2007$ & $17: 26$ & 0.31 & 2.76 & 0.018 & 298.20 & -36.5 & $-18,6$ & $+6,2$ & $+1,6$ \\
3 & $08 / 09 / 2008$ & $17: 32$ & 0.34 & 3.60 & 0.018 & 300.74 & -2.8 & $-4,0$ & $+5,2$ & $+2,3$ \\
4 & $15 / 10 / 2008$ & $17: 25$ & 0.39 & 3.75 & 0.018 & 297.15 & -1.9 & $-3,4$ & $+4,5$ & $+1,2$ \\
5 & $12 / 09 / 2009$ & $17: 45$ & 0.38 & 5.80 & 0.018 & 293.80 & -53.1 & $-24,6$ & $+5,9$ & $+1,5$ \\
6 & $21 / 07 / 2009$ & $18: 24$ & 0.38 & 5.83 & 0.017 & 301.15 & -55.4 & $-22,8$ & $+7,4$ & $+5,2$ \\
7 & $22 / 07 / 2009$ & $12: 12$ & 0.59 & 4.62 & 0.017 & 301.49 & -93.1 & $+8,5$ & $+10,2$ & $+5,8$ \\
8 & $12 / 04 / 2011$ & $09: 53$ & 0.17 & 3.06 & 0.018 & 292.29 & -24.4 & $-6,6$ & $+2,8$ & $+0,6$ \\
9 & $22 / 08 / 2011$ & $18: 05$ & 0.24 & 4.65 & 0.018 & 302.63 & -16.9 & $-16,3$ & $+4,3$ & $+2,2$ \\
10 & $01 / 09 / 2011$ & $18: 54$ & 0.23 & 3.55 & 0.017 & 300.68 & -0.5 & $-1,3$ & $+3,7$ & $+1,5$ \\
11 & $28 / 06 / 2012$ & $18: 47$ & 0.50 & 4.33 & 0.018 & 302.05 & -12.1 & $-16,4$ & $+9,3$ & $+4,2$ \\
Mn & - & - & 0.35 & 4.26 & 0.018 & 298.93 & -31.9 & -11.0 & +6.0 & +2.6 \\
\hline
\end{tabular}

Table 4. Parameters of interest for the calculation of the SW radiative forcings for the 11 cases. Time refers to the lidar start time (all lidar measurements are of a duration of $30 \mathrm{~min}$.). $\theta_{z}$ is the solar zenith angle. AOD is the AOD measured by the sun-photometer at $500 \mathrm{~nm} . \omega_{0}$ and $g$ are, respectively, the single-scattering albedo and the asymmetry factor retrieved by the sun-photometer at $440 \mathrm{~nm}$. Mn stands for "Mean".

\begin{tabular}{lcccccc}
\hline Case & Day & Time & $\begin{array}{c}\theta_{z} \\
\left.{ }^{\circ}\right]\end{array}$ & AOD & $\omega_{0}$ & $g$ \\
\hline 1 & $21 / 05 / 2007$ & $16: 11$ & 56.8 & 0.28 & 0.91 & 0.71 \\
2 & $24 / 05 / 2007$ & $17: 26$ & 67.6 & 0.31 & 0.92 & 0.73 \\
3 & $08 / 09 / 2008$ & $17: 32$ & 88.3 & 0.34 & 0.92 & 0.74 \\
4 & $15 / 10 / 2008$ & $17: 25$ & 88.8 & 0.39 & 0.94 & 0.76 \\
5 & $12 / 05 / 2009$ & $17: 45$ & 80.3 & 0.38 & 0.93 & 0.74 \\
6 & $21 / 07 / 2009$ & $18: 24$ & 77 & 0.38 & 0.79 & 0.75 \\
7 & $22 / 07 / 2009$ & $12: 12$ & 21.1 & 0.59 & 0.83 & 0.77 \\
8 & $12 / 04 / 2011$ & $09: 53$ & 41.0 & 0.17 & 0.94 & 0.71 \\
9 & $22 / 08 / 2011$ & $18: 05$ & 83.3 & 0.24 & 0.92 & 0.72 \\
10 & $01 / 09 / 2011$ & $18: 54$ & 86.2 & 0.23 & 0.93 & 0.72 \\
11 & $28 / 06 / 2012$ & $18: 47$ & 86.1 & 0.50 & 0.91 & 0.74 \\
$\mathrm{Mn}$ & - & - & & 0.35 & 0.90 & 0.74 \\
\hline
\end{tabular}

at morning/noon time, all cases are in the afternoon. The AOD varies between 0.17 (case 8) and 0.59 (case 7). The mean value is 0.35 , close to the value found for the MD model (0.37). The thickness of the MD layers is quite large: it varies between 2.76 (case 2) and $5.83 \mathrm{~km}$ (case 7). Figure 8 shows the vertical profiles of the 11 cases. A large variability of the dust vertical distribution is observed: the top of the MD layers varies between $\sim 3.3 \mathrm{~km}$ (case 2 ) and $\sim 7.2 \mathrm{~km}$ (case 6 ). Inside the layers the extinction coefficient varies commonly between 50 and $180 \mathrm{Mm}^{-1}$ with peaks up to $250 \mathrm{Mm}^{-1}$ (case 4). Some characteristics of the aerosol radiative properties in the SW spectral range are given in Table 4. The AERONET-derived single-scattering albedo at $440 \mathrm{~nm}$ varies essentially between 0.90 and 0.94 , except for cases $6(0.79)$ and $7(0.83)$ which are cases of MD with strong absorbing properties - see Sicard et al. (2012) and the discussion hereafter. The AERONET-derived asymmetry factor at $440 \mathrm{~nm}$ is quite stable between 0.71 and 0.77 . While our values of $\omega_{0}$ are in agreement with the values of Valenzuela et al. (2012) measured in Southeastern Spain, our values of $g$ are higher - Valenzuela et al. (2012) found values of $g$ at $440 \mathrm{~nm}$ of $0.70 \pm 0.02$. That difference is probably the result of their less restrictive dust classification method based on back-trajectory analysis. The range of our values of $\omega_{0}$ and $g$ is in total agreement with the calculations of the same parameters derived from measured size distribution inside a dust plume over the Canary Islands (Otto et al., 2007).

In order to check the suitability of GAME to estimate correctly the outgoing LW radiation (OLR) at the TOA, fluxes simulated with GAME are compared to those measured by CERES (Fig. 9) for the 11 cases. At the surface such a comparison is not possible because of the lack of flux measurements in the LW spectral range in Barcelona. CERES measurements are either from the AQUA satellite (overpass over Barcelona between 1200 and 1300 UT) or from the TERRA satellite (overpass over Barcelona between 1000 and 1030 UT). The uncertainty on CERES OLR has been calculated as $2.9 \%$ of the OLR value. This uncertainty corresponds to the CERES instantaneous LW TOA flux uncertainty for Terra Angular Distribution Models (ADMs), in the mid-latitude region and for clear-sky available at https://eosweb.larc.nasa.gov/sites/default/files/project/ceres/ quality_summaries/ssf_toa_terra_ed2B.pdf. The time difference between CERES and the lidar measurements (taken as the instantaneous simulation time in GAME) is not relevant 


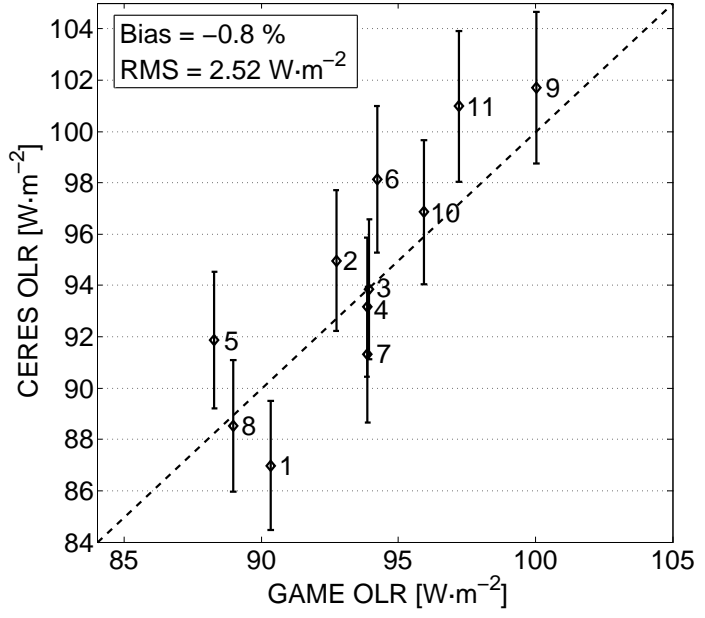

Figure 9. Comparison of the outgoing LW radiation simulated by GAME with that measured by CERES at the TOA. The number beside each diamond is the case number (see Table 3 ).

- neither in terms of solar LW radiation since the latter is nearly constant during daytime hours, nor in terms of surface albedo since the latter is also quite constant (see Sect. 3.2.2). The only parameter on which the time difference could have an impact is the surface temperature. Another difference is the spectral range: CERES measurements are in the spectral range of its WN "window" defined between 8.1 and $11.8 \mu \mathrm{m}$ whereas the fluxes calculated by GAME are in the range $8.06-11.9 \mu \mathrm{m}$. Figure 9 shows a moderate variability of the points around the $1 / 1$ line which is reflected by a root mean square $(\mathrm{rms})$ of $2.52 \mathrm{~W} \mathrm{~m}^{-2}$. However, there are approximately the same number of points above and below the 1/1 line which means that GAME OLR does not present a systematic bias compared to CERES OLR. The normalized bias, equal to $-0.8 \%$, is very low indeed. We would like to draw attention to the difficulties of extracting any magnitude from CERES footprint radiance in coastal areas, such as Barcelona. In such areas some footprints are not representative either of land or of sea because they contain information from both sources. Except for cases 1, 5, 6 and 11, GAME OLR falls within the CERES error bar. The quantitative agreement between the observed and modelled OLR provides an important check on the accuracy of GAME.

To perform the LW calculations with GAME, the refractive index has been taken as in Table 1. The MD size distribution and concentration were taken from the AERONET sunphotometer level 2.0 inversion products the closest in time to the lidar measurement time. For each case the profiles of pressure, temperature and relative humidity were taken from the radiosoundings at 1200 UT of the corresponding day. The surface albedo was calculated from the surface emissivity available in the CERES SSF Level 2 products. The surface temperature was taken from the same products. The AOD
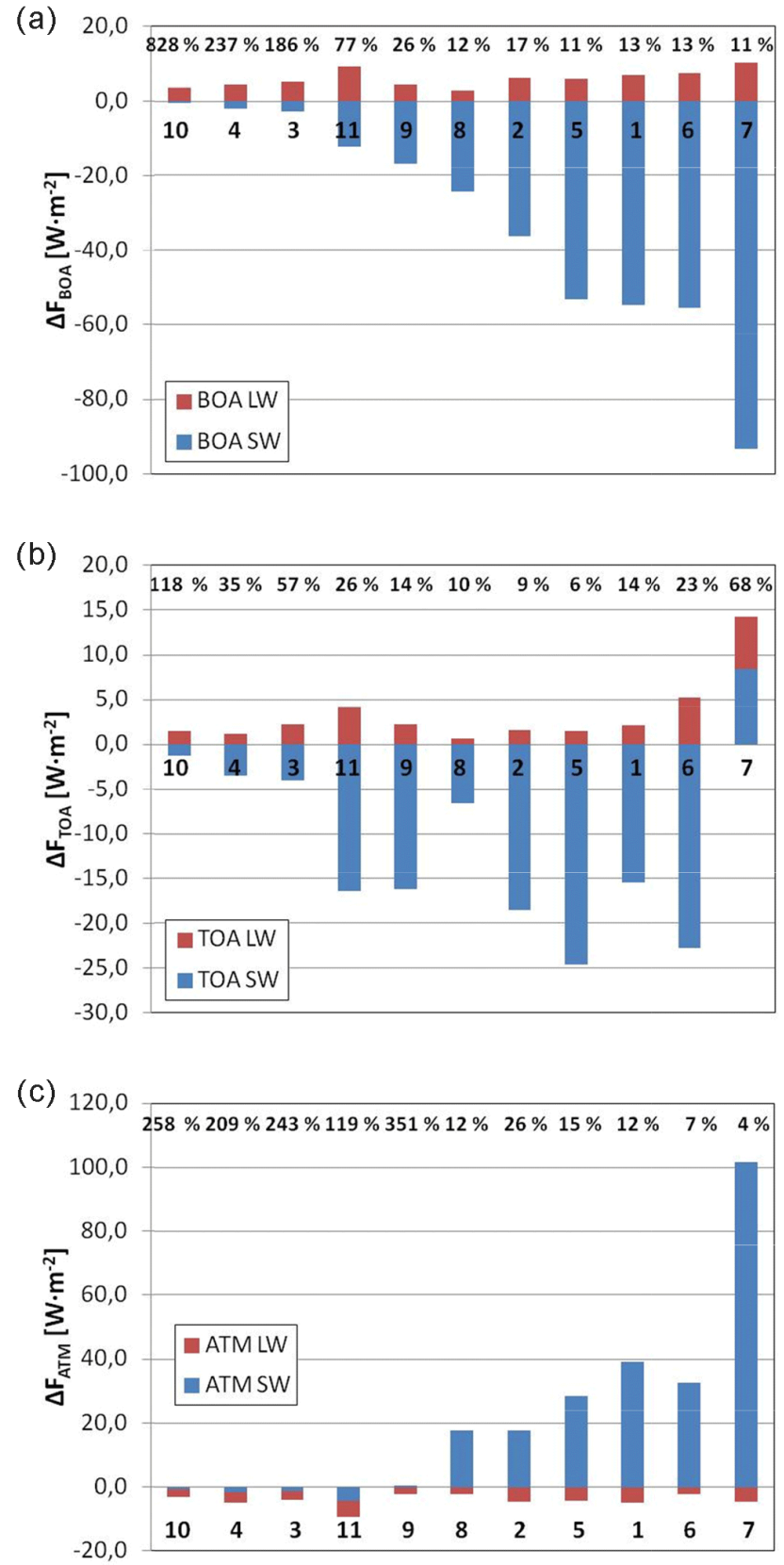

Figure 10. Instantaneous SW and LW RF (a) at the BOA, (b) at the TOA and (c) in the whole atmosphere for the 11 cases. The case number (see Table 3 ) is indicated below the abscissa axis. The cases are ordered by increasing SW RF (in absolute value) at the BOA. Percentages on top of the graphs represent the LW / SW forcing ratio.

vertical distribution was retrieved by means of lidar-derived extinction profiles at $532 \mathrm{~nm}$.

The SW and LW RF calculated by GAME at the BOA and at the TOA for the 11 cases of MD are given in Table 3 and represented in Fig. 10a and 9b. The RF of the aerosols in the whole atmospheric column is represented in Fig. 10c. At the 
BOA (Fig. 10a) the SW RF has always a cooling effect and varies from -93.1 to $-0.5 \mathrm{~W} \mathrm{~m}^{-2}$ while the $\mathrm{LW} \mathrm{RF}$ has always a heating effect and varies from +2.8 to $+10.2 \mathrm{~W} \mathrm{~m}^{-2}$. The range of values of the SW RF is consistent with forcing measurements made in southwestern Spain during the summer season (Horvath et al., 2002; Cachorro et al., 2008), in a coastal city in southern Italy (Perrone and Bergamo, 2011), over a French Mediterranean coastal zone (Saha et al., 2008) and with Meloni et al. (2003) who found at the island of Lampedusa $-70.8 \mathrm{~W} \mathrm{~m}^{-2}$ at the BOA for an AOD of 0.511 at $415 \mathrm{~nm}$. It is interesting to compare those numbers to the summer, regional mean value over the broader Mediterranean Basin of $-26.5 \mathrm{~W} \mathrm{~m}^{-2}$ found by Papadimas et al. (2012). The values of the LW RF are consistent with results obtained by Liao and Seinfeld (1998) and Highwood et al. (2003) among others. At a regional scale over West Africa and during an intense dust event, Mallet et al. (2009) found an instantaneous (at noon) SW RF at the BOA similar $\left(-86.6 \mathrm{~W} \mathrm{~m}^{-2}\right)$ to case 7 for an AOD of 0.6 at $560 \mathrm{~nm}$ and a LW RF larger $\left(+15.9 \mathrm{~W} \mathrm{~m}^{-2}\right)$. In the cases with low SW RF (3, 4 and 10) and thus with less impact on the Earth radiative budget, the LW RF is higher than the SW RF (in absolute values). The lower SW RF calculated for those cases is due to the low incoming solar radiation at the date and time of the RF estimation. All three cases are in the afternoon and in September or October: cases 3, 4 and 10 have a solar zenith angle of $88.3,88.8$ and $86.2^{\circ}$, respectively. In the other cases the LW RF represents between 11 and $26 \%$ (with opposite sign) of the SW RF, except in case 11 for which the LW contribution is $77 \%$ (with opposite sign). Di Sarra et al. (2011) found instantaneous LW/SW RF ratio at the BOA on the order of $20 \%$ at Lampedusa. Perrone and Bergamo (2011) found values of 9-22\% in a coastal city in southern Italy. We note that the SW RF of case 11 is the lowest one $\left(-12.1 \mathrm{~W} \mathrm{~m}^{-2}\right)$ after the cases 3,4 and 10 . The highest LW $\mathrm{RF}\left(+10.2 \mathrm{~W} \mathrm{~m}^{-2}\right)$ is produced by the case with the highest AOD (case 7) as expected from the sensitivity analysis (see Fig. 7a). Note also that case 2, the case with the lowest vertical extension of MD (see Fig. 8) produces a relatively high LW RF $\left(+6.2 \mathrm{~W} \mathrm{~m}^{-2}\right)$ at the BOA because of its proximity to the surface (see Fig. 7b).

At the TOA (Fig. 10b) the aerosols have also a cooling effect in the SW spectral range (except for case 7, see explanation below) with a $\mathrm{RF}$ ranging from -24.6 to $-1.3 \mathrm{~W} \mathrm{~m}^{-2}$. Comparable values were found in a coastal city in southern Italy (Perrone and Bergamo, 2011) and over a French Mediterranean coastal zone (Saha et al., 2008). Here again it is interesting to compare those numbers to the summer, regional mean value over the broader Mediterranean Basin of $-6.3 \mathrm{~W} \mathrm{~m}^{-2}$ found by Papadimas et al. (2012). In the LW spectral range they have a heating effect with a RF ranging from +0.6 to $+5.8 \mathrm{~W} \mathrm{~m}^{-2}$. The $\mathrm{LW}$ values are comparable to estimations made from satellite data by Zhang and Christopher (2003) and near the MD source region (Highwood et al., 2003). Here again the contribution of the LW RF is high for the three cases with low SW RF. In the other cases (except case 7) the LW contribution varies between 6 and $26 \%$ (with opposite sign). Di Sarra et al. (2011) found instantaneous LW/SW RF ratio at the TOA of the order of $17 \%$ at Lampedusa. Perrone and Bergamo (2011) found values of $8-14 \%$ in a coastal city in southern Italy. Case 7, thoroughly documented in Sicard et al. (2012), presents the highest AOD, the second lowest single scattering albedo (0.83 at $440 \mathrm{~nm}$ ) and the highest imaginary part of the refractive index $(0.01$ at $440 \mathrm{~nm})$. By comparing those results to other studies such as Dubovik et al. (2002) and by looking at CALIPSO (Cloud-Aerosol Lidar and Infrared Pathfinder Satellite Observations) aerosol subtyping observations and MODIS (Moderate Resolution Imaging Spectroradiometer) images, Sicard et al. (2012) concluded that the strong absorbing properties of that case might be due to a mixing of dust with polluted and smoke aerosols. Such a case is remarkable since the strong absorbing properties counteract the usually predominant scattering ones resulting in an unusual positive SW RF at the TOA. One sees that cases 6 and 7 which have the highest vertical extension of MD (see Fig. 8) produce the strongest LW RF at the TOA (see Table 3) as expected from the sensitivity analysis (see Fig. 7b).

The contribution of the aerosols in the whole atmospheric column is quantified by the atmospheric forcing, $\Delta F_{\mathrm{ATM}}$, defined as

$\Delta F_{\mathrm{ATM}}=\Delta F_{\mathrm{TOA}}-\Delta F_{\mathrm{BOA}}$.

The atmospheric forcing is shown in Fig. 10c. If we leave aside all cases for which the SW atmospheric forcings are low, i.e. $\left|\Delta F_{\mathrm{ATM}}\right|<+5 \mathrm{~W} \mathrm{~m}^{-2}$ (cases 3, 4, 9, 10 and 11), the $\mathrm{SW} \Delta F_{\mathrm{ATM}}$ is positive and ranges from +17.8 to +39.3 (for case 7 it is exceptionally high, $+101.5 \mathrm{~W} \mathrm{~m}^{-2}$, since the two components at the BOA and at the TOA sum up). For comparison, these values are found to be consistent with those obtained by Mallet at al. (2008) who measured atmospheric forcings slightly higher, $+43.1 \mathrm{~W} \mathrm{~m}^{-2}$, near the dust source and for higher aerosol loads (AOD of 1.06 at $440 \mathrm{~nm}$ ). Papadimas et al. (2012) found a summer, regional mean atmospheric SW RF over the broader Mediterranean Basin of $+20.1 \mathrm{~W} \mathrm{~m}^{-2}$. The LW $\Delta F_{\mathrm{ATM}}$ is negative ranging from -4.8 to $-2.2 \mathrm{~W} \mathrm{~m}^{-2}$, and represents between 4 and $26 \%$ (with opposite sign) of the SW component. Di Sarra et al. (2011) found instantaneous LW/SW RF ratio in the atmosphere of the order of $24 \%$ at Lampedusa. Slingo et al. (2006) demonstrated that, in high MD loads $(1<$ AOD < 4), RTM underestimate slightly the solar absorption within the atmosphere. Assuming that this tendency persists in cases with lower MD loads, SW $\Delta F_{\mathrm{ATM}}$ might be underestimated and therefore the LW / SW ratio overestimated.

The aerosol heating/cooling rate has been computed from GAME as described in Roger et al. (2006). The profiles of heating/cooling rate are shown in Fig. 11. For the sake of clarity all cases are not plotted in the figure. The cases with low SW RF (cases 3, 4 and 10) have been discarded. 


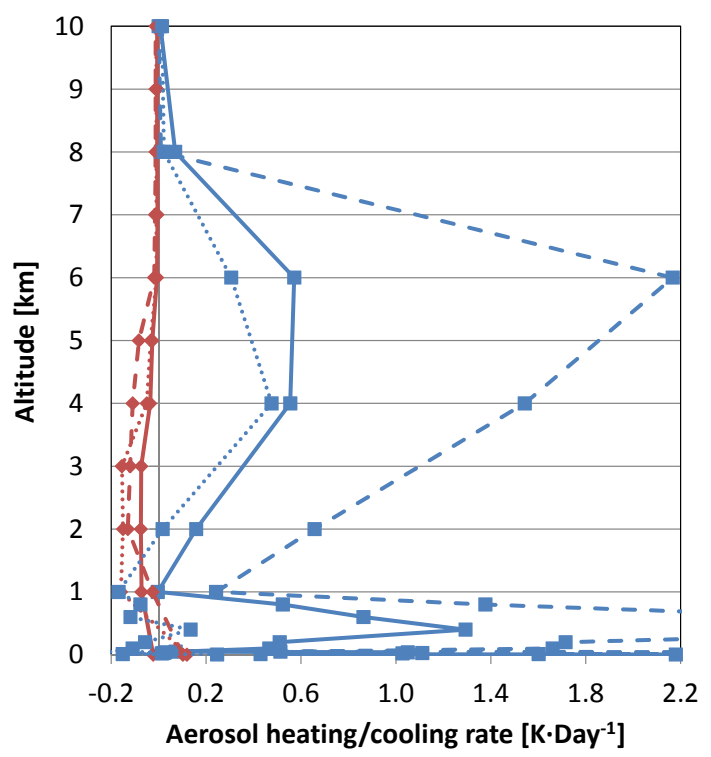

Figure 11. Aerosol heating/cooling rate in the LW (red lines) and in the SW (blue lines) spectral range for case 11 (strongest SW RF at the BOA, dashed line), case 7 (lowest SW RF at the BOA, dotted line) and the mean of all cases, excepting cases 3, 4 and 10 (solid line).

Among the other cases we have represented the case with the strongest (in absolute value) SW RF (case 11), the one with the lowest SW RF (case 7) and the mean of all cases. The amplitude of the SW heating rate of case 11 is similar to that estimated by Guerrero-Rascado et al. (2009) of a dust intrusion in southern Spain with similar AOD. The mean SW heating rate profile reaches $0.55-0.57 \mathrm{~K} \mathrm{day}^{-1}$ between 4 and $6 \mathrm{~km}$, while the mean LW cooling rate profile reaches $-0.07 \mathrm{~K} \mathrm{day}^{-1}$ between 1 and $3 \mathrm{~km}$. For all cases the peak of the SW heating rate profile occurs at a higher altitude than the peak of the LW cooling rate profile. Quantitatively, the mean profile is in good agreement with results from Fouquart et al. (1987), for example, who found daily averaged SW heating rate of $0.7 \mathrm{~K} \mathrm{day}^{-1}$ and LW cooling rates of $0.2 \mathrm{~K}$ day $^{-1}$ for a SW AOD of 0.32. A heating, related to the temperature gradient between the ground and the atmosphere, is visible near the surface for both cases $7\left(0.1 \mathrm{~K} \mathrm{day}^{-1}\right)$ and 11 $\left(0.12 \mathrm{~K} \mathrm{day}^{-1}\right)$. This is not systematic for the other cases.

\section{Conclusions}

This work quantifies the sensitivity of the aerosol direct LW $\mathrm{RF}$ including absorption and scattering effects to MD particle microphysical and optical properties, dust plume load (in terms of AOD) and height, as well as surface temperature and surface albedo. The sensitivity study was performed with a particle model (fine- and coarse-mode radius of 0.057 and $0.649 \mu \mathrm{m}$, respectively, and AOD of 0.37 ) representative of the typical long-range transported mineral dust in Barcelona and based on almost 8 years of AERONET sun-photometer measurements. It shows that:

- The LW RF has a quasi-linear relationship (with a positive slope) with the AOD both at the BOA and at the TOA.

- The closer the dust plume to the BOA/TOA, the highest the LW RF at the BOA/TOA. A mid-point exists at $\sim 3.5 \mathrm{~km}$ where the LW RF at the BOA and at the TOA are equal.

- The LW RF is highly dependent on the coarse mode of the dust size distribution: it becomes significant for radii greater than $0.1 \mu \mathrm{m}$ and increases strongly up to radii of $1 \mu \mathrm{m}$. Between those two radii the dust absorption and the scattering increase.

- The LW RF becomes significant for coarse/fine mode ratio, $N_{\mathrm{c}} / N_{\mathrm{f}}$, greater than $10^{-4}$ and increases strongly up to $10^{-2}$. The LW RF produced by MD with a size distribution dominated by small particles represents only $14 \%$ at the BOA and less than $10 \%$ at the TOA compared to that produced by a size distribution dominated by large particles.

- For radii lower than $0.1 \mu \mathrm{m}$ the scattering properties have no effect on the LW RF. For radii greater than $0.1 \mu \mathrm{m}$, the scattering effect contributes to the LW RF up to $18 \%$ at the BOA and up to $38 \%$ at the TOA. The highest contribution is reached for particles with a radius of $0.5 \mu \mathrm{m}$.

The short-wave and long-wave direct radiative forcing of mineral dust has been estimated in 11 daytime cases over the period 2007-2012 in Barcelona. Measurements from lidar, sun-photometer and satellite were used to constrain the radiative transfer model. We have found that the LW RF varies between +2.8 and $+10.2 \mathrm{~W} \mathrm{~m}^{-2}$ at the BOA and between +0.6 and $+5.8 \mathrm{~W} \mathrm{~m}^{-2}$ at the TOA. This represents between 11 and $26 \%$ (with opposite sign) at the BOA and between 6 and $26 \%$ (with opposite sign) at the TOA of the SW component. The LW / SW ratio has no marked tendency with increasing SW RF, neither at the BOA, nor at the TOA. The $\mathrm{LW}$ atmospheric forcing varies from -4.8 to $-2.2 \mathrm{~W} \mathrm{~m}^{-2}$, while the atmospheric LW/SW ratio varies from 4 to $26 \%$ (with opposite sign) and roughly decreases with increasing SW RF. As the LW/SW ratio can reach $26 \%$ at all levels (BOA, TOA and in the atmosphere) it is recommended not to neglect the direct $\mathrm{LW}$ radiative forcing produced by mineral dust even in daytime studies, unless the authors can explicitly demonstrate that its contribution is small compared to the SW forcing. 
The aerosol properties to which the LW RF is sensitive, such as size distribution and concentration, are highly variable with transport. Because of the lack of knowledge of the aerosol properties in the LW range, MD particles remain difficult to accurately parameterize at a large geographical scale in regional and global climate models: the dust load and size distribution as well as the height of the dust plume, on which the LW RF is strongly dependent, are spatially highly variable. In that sense, this study may help to estimate the LW component of the net (short-wave plus long-wave) radiative forcing in other Mediterranean regions where the dust load is similar to that of Barcelona. 
Appendix A: AERONET size distributions are bimodal volumetric lognormal distributions

$\frac{\partial V(r)}{\partial \ln r}=V(r) \frac{\partial N(r)}{\partial \ln r}=\frac{4}{3} \pi r^{3} \frac{\partial N(r)}{\partial \ln r}$,

where $V$ is the volume, $r$ the particle radius and $N$ the particle number. The definitions of the volume median radius, $r_{\mathrm{V}}$, and its associated standard deviation, $\sigma_{\mathrm{V}}$, can be found at http://aeronet.gsfc.nasa.gov/new_web/Documents/ Inversion_products_V2.pdf. The fine- and coarse-mode separation technique is also explained in the same reference. The median radius of the lognormal distribution (input of the Mie code) relates to $r_{\mathrm{V}}$ and $\sigma_{\mathrm{V}}$ as

$r_{\mathrm{g}}=r_{\mathrm{V}} e^{-3\left(\ln \sigma_{\mathrm{g}}\right)^{2}}$
The standard deviation associated to $r_{\mathrm{g}}$ is

$\sigma_{\mathrm{g}}=\sigma_{\mathrm{V}}$

The volume concentration, $C_{\mathrm{V}}$, refers to the integration of the volumetric lognormal distribution between minimum and maximum radius:

$C_{\mathrm{V}}=\int_{r_{\min }}^{r_{\max }} \frac{\partial V(r)}{\partial \ln r} \partial \ln r$.

From Eqs. (3) and (6) the particle number is derived from

$N=\frac{3 C_{\mathrm{V}}}{2 \pi r_{\mathrm{V}}^{3} e^{-\frac{9}{2} \sigma \mathrm{V}}\left[\operatorname{erf}\left(\frac{\ln r_{\max }-\ln r_{\mathrm{V}}}{\sqrt{2} \sigma}\right)-\operatorname{erf}\left(\frac{\ln r_{\min }-\ln r_{\mathrm{V}}}{\sqrt{2} \sigma}\right)\right]}$. 
Acknowledgements. This study was performed in the framework of work package 4 on aerosol-radiation-climate interactions of the coordinated programme ChArMEx (the Chemistry-Aerosol Mediterranean Experiment; http://charmex.lsce.ipsl.fr). This work is supported by the 7th Framework Programme project Aerosols, Clouds, and Trace Gases Research Infrastructure Network (ACTRIS) (grant agreement no. 262254); by the Spanish Ministry of Science and Innovation and FEDER funds under the projects TEC2012-34575, TEC2009-09106/TEC, CGL2011-13580-E/CLI and CGL2011-16124-E/CLI. The Earth Sciences Division of the Barcelona Supercomputing Center is acknowledged for the use of the Barcelona AERONET sun-photometer data.

Edited by: F. Dulac

\section{References}

Basart, S., Pérez, C., Cuevas, E., Baldasano, J. M., and Gobbi, G. P.: Aerosol characterization in Northern Africa, Northeastern Atlantic, Mediterranean Basin and Middle East from direct-sun AERONET observations, Atmos. Chem. Phys., 9, 8265-8282, doi:10.5194/acp-9-8265-2009, 2009.

Berk, A., Anderson, G. P., Acharya, P. K., Bernstein, L. S., Muratov, L., Lee, J., Fox, M., Adler-Golden, S. M., Chetwynd, J. H., Hoke, M. L., Lockwood, R. B., Gardner, J. A., Cooley, T. W., Borel, C. C., Lewis, P. E., and Shettle, E. P.: MODTRAN5: 2006 Update, Proc. SPIE, Vol. 6233, 62331F, 2006.

Cachorro, V. E., Toledano, C., Prats, N., Sorribas, M., Mogo, S., Berjón, A., Torres, B., Rodrigo, R., de la Rosa, J., and De Frutos, A. M.: The strongest desert dust intrusion mixed with smoke over the Iberian Peninsula registered with Sun photometry, J. Geophys. Res. 113, D14S04, doi:10.1029/2007JD009582, 2008.

Chou, C., Formenti, P., Maille, M., Ausset, P., Helas, G., Harrison, M., and Osborne, S.: Size distribution, shape, and composition of mineral dust aerosols collected during the African Monsoon Multidisciplinary Analysis Special Observation Period 0: Dust and Biomass-Burning Experiment field campaign in Niger, January 2006, J. Geophys. Res. 113, D00C10, doi:10.1029/2008JD009897, 2008.

Claquin, T., Schulz, M., Balkanski, Y., and Boucher, O.: Uncertainties in assessing radiative forcing by mineral dust. Tellus 50B, 491-505, 1998.

Clough, S., Kneizys, F., and Davies, R.: Line shape and the water vapor continuum, Atmos. Res. 23, 229-241, 1989.

d'Almeida, G., Koepke, P., and Shettle, E.: Atmospheric aerosols: global climatology and radiative characteristics, A. Deepak Pub., Hampton, VA, 57 pp., 1991.

di Sarra, A., Di Biagio, C., Meloni, D., Monteleone, F., Pace, G., Pugnaghi, S., and Sferlazzo, D.: Shortwave and longwave radiative effects of the intense Saharan dust event of 25-26 March, 2010, at Lampedusa (Mediterranean sea), J. Geophys. Res. 116, D23209, doi:10.1029/2011JD016238, 2011.

Dubovik, O. and King, M. D.: A flexible inversion algorithm for retrieval of aerosol optical properties from Sun and sky radiance measurements", J. Geophys. Res. 105, 20673-20696, 2000.

Dubovik, O., Smirnov, A., Holben, B. N., King, M. D., Kaufman, Y. J., Eck, T. F., and Slutsker, I.: Accuracy assessment of aerosol optical properties retrieval from AERONET sun and sky radiance measurements, J. Geophys. Res 105, 9791-9806, 2000.
Dubovik, O., Holben, B., Eck, T., Smirnov, A., Kaufman, Y., King, M., Tanré, D., and Slutsker, I.: Variability of Absorption and Optical Properties of Key Aerosol Types Observed in Worldwide Locations, J. Atmos. Sci. 59, 590-608, 2002.

Dubuisson, P., Buriez. J. C., and Fouquart, Y.: High spectral resolution solar radiative transfer in absorbing and scattering media: Application to the satellite simulation, J. Quant. Spectrosc. Radiat. Transfer. 55, 103-126, 1996.

Dubuisson, P., Dessailly, D., Vesperini, M., and Frouin, R.: Water Vapor Retrieval Over Ocean Using Near-Infrared Radiometry, J. Geophys. Res., 109, D19106, doi:10.1029/2004JD004516, 2004.

Dubuisson, P., Giraud, V., Chomette, O., Chepfer, H., and Pelon, J.: Fast radiative transfer modeling for infrared imaging radiometry, J. Quant. Spectrosc. Radiat. Transfer 95, 201-220, 2005.

Dubuisson, P., Roger, J., Mallet, M., and Dubovik, O.: A Code to Compute the Direct Solar Radiative Forcing: Application to Anthropogenic Aerosols during the Escompte Experiment, Proc. International Radiation Symposium (IRS 2004) on Current Problems in Atmospheric Radiation, edited by: Fischer, H., Sohn, B.J., and Deepak, A., Hampton, 127-130, 23-28 August 2004, Busan, Korea, 2006.

Dufresne, J., Gautier, C., and Ricchiazzi, P.: Longwave scattering effects of mineral aerosols, J. Atmos. Sci. 59, 1959-1966, 2002.

Forster, P., Ramaswamy, V., Artaxo, P., Berntsen, T., Betts, R., Fahey, D. W., Haywood, J., Lean, J., Lowe, D. C., Myhre, G., Nganga, J., Prinn, R., Raga, G., Schulz, M., and Van Dorland, R.: Changes in atmospheric constituents and in radiative forcing, in Climate Change 2007, The Physical Science Basis. Contribution of Working Group I to the Fourth Assessment Report of the Intergovernmental Panel on Climate Change, edited by: Solomon, S., Qin, D., Manning, M., Chen, Z., Marquis, M., Averyt, K. B., Tignor, M., and Miller H. L., Cambridge Univ. Press, Cambridge, UK, 129-234, 2007.

Fouquart, Y., Bonnel, B., Brogniez, G., Buriez, J., Smith, L., Morcrette, J., and Cerf, A.: Observations of Saharan aerosols: Results of ECLATS field experiment. Part II: Broadband radiative characteristics of the aerosols and vertical radiative flux divergence, J. Clim. Meteor. 26, 38-52, 1987.

Gobbi, G. P., Kaufman, Y. J., Koren, I., and Eck, T. F.: Clasification of aerosol properties derived from AERONET direct sun data, Atmos. Chem. Phys. 7, 453-458, 2007.

Gómez-Amo, J. L., di Sarra, A., Meloni, D., Cacciani, M., and Utrillas, M. P.: Sensitivity of shortwave radiative fluxes to the vertical distribution of aerosol single scattering albedo in the presence of a desert dust layer, Atmos. Environ. 44, 2787-2791, 2010.

Guerrero-Rascado, J. L., Olmo, F. J., Avilés-Rodríguez, I., NavasGuzmán, F., Pérez-Ramírez, D., Lyamani, H., and Alados Arboledas, L.: Extreme Saharan dust event over the southern Iberian Peninsula in september 2007: active and passive remote sensing from surface and satellite, Atmos. Chem. Phys. 9, 84538469, doi:10.5194/acp-9-8453-2009, 2009.

Hansell, R. A., Tsay, S. C., Ji, Q., Hsu, N. C., Jeong, M. J., Wang, S. H., Reid, J. S., Liou, K. N., and Ou, S. C.: An assessment of the surface longwave direct radiative effect of airborne saharan dust during the NAMMA field campaign, J. Atmos. Sci. 67, 10481065, doi:10.1175/2009JAS3257.1, 2010.

Haywood, J. M., Johnson, B. T., Osborne, S. R., Mulcahy, J., Brooks, M., Harrison, M. A. J., Milton, S. F., and Brindley, H. E.: Observations and modelling of the solar and terrestrial 
radiative effects of Saharan dust: a radiative closure case-study over oceans during the GERBILS campaign. Q. J. R. Meteorol. Soc. 137, 1211-1226, doi:10.1002/qj.770, 2011.

Hess, M., Koepke, P., and Schult, I.: Optical Properties of Aerosols and Clouds: The Software Package OPAC, Bull. Amer. Meteor. Soc. 79, doi:10.1175/15200477(1998)079<0831:OPOAAC>2.0.CO;2, 1998.

Highwood, E., Haywood, J., Silverstone, M., Newman, S. M., and Taylor, J.: Radiative properties and direct effect of Saharan dust measured by the C-130 aircraft during Saharan Dust Experiment (SHADE): 2. Terrestrial spectrum, J. Geophys. Res. 2003, 108, D188578, doi:10.1029/2002JD002552, 2003.

Holben, B. N., Eck, T. F., Slutsker, I., Tanre, D., Buis, J. P., Setzer, A., Vermote, E., Reagan, J. A., Kaufman, Y. J., Nakajima, T., Lavenu, F., Jankowiak, I., and Smirnov, A.: AERONET: A federated instrument network and data archive for aerosol characterization, Remote Sens. Environ. 66, 1-16, 1998.

Horvath, H., Arboledas, L. A., Olmo, F. J., Jovanovic, O., Gangl, M., Kaller, W., Sanchez, C., Sauerzopf, H., and Seidl, S.: Optical characteristics of the aerosol in Spain and Austria and its effect on radiative forcing, J. Geophys. Res. 107, D194386, 4386, doi:10.1029/2001JD001472, 2002.

IPCC, Climate Change 2013: The Physical Science Basis, the Working Group I contribution to the UN IPCC's Fifth Assessment Report (WG1 AR5), Cambridge University Press, New York, USA, 159-254, 2013.

Kaufman, Y. J., Tanré, D., and Boucher, O.: A satellite view of aerosols in the climate system, Nature, 419, 215-223, 2002.

Key, J. and Schweiger, A. J.: Tools for atmospheric radiative transfer: Streamer and FluxNet, Comp. Geosci., 24, 443-451, doi:10.1016/S0098-3004(97)00130-1, 1998.

Köhler, C. H., Trautmann, T., Lindermeir, E., Vreeling, W., Lieke, K., Kandler, K., Weinzierl, B., Groß, S., Tesche, M., and Wendisch, M.: Thermal IR radiative properties of mixed mineral dust and biomass aerosol during SAMUM-2, Tellus B 11, 751-769, doi:10.1111/j.1600-0889.2011.00563.x, 2011.

Krekov, G. M.: Models of atmospheric aerosols, edited by: Jennings, S. G., Aerosol Effects on Climate, University of Arizona Press, Tucson, AZ, 9-72, 1993.

Lacis, A. and Oinas, V.: A description of the correlated kdistribution method, J. Geophys. Res. 96, 9027-9064, 1991.

Lau, K. M., Kim, K. M., Sud, Y. C., and Walker, G. K.: A GCM study of the response of the atmospheric water cycle of West Africa and the Atlantic to Saharan dust radiative forcing, Ann. Geophys., 27, 4023-4037, doi:10.5194/angeo-27-40232009, 2009.

Li, J., Ma, X., von Salzen, K., and Dobbie, S.: Parameterization of sea-salt optical properties and physics of the associated radiative forcing, Atmos. Chem. Phys., 8, 4787-4798, doi:10.5194/acp-84787-2008, 2008.

Liao, H. and Seinfeld, J.: Radiative Forcing by mineral dust aerosols: sensitivity to key variables, J. Geophys. Res., 103, 31637-31645, 1998.

Mallet, M., Pont, V., Liousse, C., Gomes, L., Pelon, J., Osborne, S., Haywood, J., Roger, J., Dubuisson, P., Mariscal, A., Thouret, V., and Goloub, P.: Aerosol direct radiative forcing over Djougou (northern Benin) during the African Monsoon Multidisciplinary Analysis dry season experiment (Special Observation Period-
0), J. Geophys. Res. 113, D00C01, doi:10.1029/2007JD009419, 2008.

Mallet, M., Tulet, P., Serça, D., Solmon, F., Dubovik, O., Pelon, J., Pont, V., and Thouron, O.: Impact of dust aerosols on the radiative budget, surface heat fluxes, heating rate profiles and convective activity over West Africa during March 2006, Atmos. Chem. Phys., 9, 7143-7160, doi:10.5194/acp-9-7143-2009, 2009.

Marconi, M., Sferlazzo, D. M., Becagli, S., Bommarito, C., Calzolai, G., Chiari, M., di Sarra, A., Ghedini, C., Gómez-Amo, J. L., Lucarelli, F., Meloni, D., Monteleone, F., Nava, S., Pace, G., Piacentino, S., Rugi, F., Severi, M., Traversi, R., and Udisti, R.: Saharan dust aerosol over the central Mediterranean Sea: $\mathrm{PM}_{10}$ chemical composition and concentration versus optical columnar measurements, Atmos. Chem. Phys., 14, 2039-2054, doi:10.5194/acp-14-2039-2014, 2014.

Maring, H., Savoie, D. L., Izaguirre, M. A., Custals, L., and Reid, J. S.: Mineral dust aerosol size distribution change during atmospheric transport, J. Geophys. Res. 108, 8592, doi:10.1029/2002JD002536, 2003.

Markowicz, K. M., Flatau, P. J., Vogelmann, A. M., Quinn, P. K., and Welton, E. J.: Clear-sky infrared radiative forcing at the surface and the top of the atmosphere, Q. J. Roy. Meteor. Soc. 129, 2927-2947, 2003.

Mayer, B. and Kylling, A.: Technical note: The libRadtran software package for radiative transfer calculations - description and examples of use, Atmos. Chem. Phys., 5, 1855-1877, doi:10.5194/acp-5-1855-2005, 2005.

McClatchey, R. A., Fenn, R. W., Shelby, J. E. A., Voltz, F. E., and Garing, J. S.: Optical properties of the atmosphere, Research paper AFCRF-72-0497, Hanscom Air Force Base, Bedford, 108 pp., 1972.

McConnell, C. L., Highwood, E. J., Coe, H., Formenti, P., Anderson, B., Osborne, S., Nava, S., Desboeufs, K., Chen, G., and Harrison, M. A. J.: Seasonal variations of the physical and optical characteristics of Saharan dust: Results from the Dust Outflow and Deposition to the Ocean (DODO) experiment, J. Geophys. Res. 113, D14S05, doi:10.1029/2007JD009606, 2008.

McConnell, C. L., Formenti, P., Highwood, E. J., and Harrison, M. A. J.: Using aircraft measurements to determine the refractive index of Saharan dust during the DODO Experiments, Atmos. Chem. Phys., 10, 3081-3098, doi:10.5194/acp-10-30812010, 2010.

Meloni, D., di Sarra, A., DeLuisi, J., Di Iorio, T., Fiocco, G., Junkermann, W., and Pace, G.: Tropospheric aerosols in the Mediterranean: 2. Radiative effects through model simulations and measurements, J. Geophys. Res. 108, 4317-4332, 2003.

Müller, D., Weinzierl, B., Petzold, A., Kandler, K., Ansmann, A., Müller, T., Tesche, M., Freudenthaler, V., Esselborn, M., Heese, B., Althausen, D., Schladitz, A., Otto, S., and Knippertz, P.: Mineral dust observed with AERONET Sun photometer, Raman lidar, and in situ instruments during SAMUM 2006: Shapeindependent particle properties, J. Geophys. Res. 115, D07202, doi:10.1029/2009JD012520, 2010.

Müller, D. Lee, K.-H., Gasteiger, J., Tesche, M., Weinzierl, B., Kandler, K., Müller, T., Toledano, C., Otto, S., Althausen, D., and Ansmann, A.: Comparison of optical and microphysical properties of pure Saharan mineral dust observed with AERONET Sun photometer, Raman lidar, and in situ 
instruments during SAMUM 2006, J. Geophys. Res. 117, D07211, doi:10.1029/2011JD016825, 2012.

Osada, K., Ura, S., Kagawa, M., Mikami, M., Tanaka, T. Y., Matoba, S., Aoki, K., Shinoda, M., Kurosaki, Y., Hayashi, M., Shimizu, A., and Uematsu, M.: Wet and dry deposition of mineral dust particles in Japan: factors related to temporal variation and spatial distribution, Atmos. Chem. Phys., 14, 1107-1121, doi:10.5194/acp-14-1107-2014, 2014.

Osborne, S. R., Baran, A. J., Johnson B. T., Haywood, J. M., Hesse, E., and Newman, S.: Short-wave and long-wave radiative properties of Saharan dust aerosol, Q. J. Roy. Meteorol. Soc., 137, 1149-1167, doi:10.1002/qj.771, 2011.

Otto, S., de Reus, M., Trautmann, T., Thomas, A., Wendisch, M., and Borrmann, S.: Atmospheric radiative effects of an in situ measured Saharan dust plume and the role of large particles, Atmos. Chem. Phys. 7, 4887-4903, doi:10.5194/acp-7-4887-2007, 2007.

Otto, S., Bierwirth, E., Weinzierl, B., Kandler, K., Esselborn, M., Tesche, M., Schladitz, A., Wendisch, M., and Trautmann, T.: Solar radiative effects of a Saharan dust plume observed during SAMUM assuming spheroidal model particles, Tellus B, 61B, 270296, doi:10.1111/j.1600-0889.2008.00389.x, 2009.

Otto, S., Trautmann, T., and Wendisch, M.: On realistic size equivalence and shape of spheroidal Saharan mineral dust particles applied in solar and thermal radiative transfer calculations, Atmos. Chem. Phys. 11, 4469-4490, doi:10.5194/acp-11-44692011, 2011.

Papadimas, C. D., Hatzianastassiou, N., Matsoukas, C., Kanakidou, M., Mihalopoulos, N., and Vardavas, I.: The direct effect of aerosols on solar radiation over the broader Mediterranean basin, Atmos. Chem. Phys., 12, 7165-7185, doi:10.5194/acp-12-71652012, 2012.

Papayannis, A., Amiridis, V., Mona, L., Tsaknakis, G., Balis, D., Bösenberg, J., Chaikovski, A., De Tomasi, F., Grigorov, I., Mattis, I., Mitev, V., Müller, D., Nickovic, S., Pérez, C., Pietruczuk, A., Pisani, G., Ravetta, F., Rizi, V., Sicard, M., Trickl, T., Wiegner, M., Gerding, M., Mamouri, R. E., D’Amico, G., and Pappalardo, G.: Systematic lidar observations of Saharan dust over Europe in the frame of EARLINET (2000-2002), J. Geophys. Res., 113, D10204, doi:10.1029/2007JD009028, 2008.

Perrone, M. R. and Bergamo, A.: Direct radiative forcing during Sahara dust intrusions at a site in the Central Mediterranean: Anthropogenic particle contribution, Atmos. Res., 101, 783-798, 2011.

Pey, J., Querol, X., Alastuey, A., Forastiere, F., and Stafoggia, M.: African dust outbreaks over the Mediterranean Basin during 2001-2011: $\mathrm{PM}_{10}$ concentrations, phenomenology and trends, and its relation with synoptic and mesoscale meteorology, Atmos. Chem. Phys., 13, 1395-1410, doi:10.5194/acp-13-13952013, 2013.

Prospero, J. M., Ginoux, P., Torres, O., Nicholson, S. E., and Gill, T. E.: Environmental characterization of global sources of atmospheric soil dust identified with the Nimbus 7 Total Ozone Mapping Spectrometer (TOMS) absorbing aerosol product, Rev. Geophys., 40, 1002, doi:10.1029/2000RG000095, 2002.

Reid, J. S., Jonsson, H. H., Maring, H. B., Smirnov, A., Savoie, D. L., Cliff, S. S., Reid, E. A., Livingston, J. M., Meier, M. M., Dubovik, O., and Tsay, S.-C.: Comparison of size and morpho- logical measurements of coarse mode dust particles from Africa, J. Geophys. Res., 108, 8493, doi:10.1029/2002JD002485, 2003.

Remer, L. A., Kleidman, R. G., Levy, R. C., Tanré, D., Mattoo, S., Vanderlei Martins, J., Ichoku, Ch., Koren, I., Yu, H., and Holben, B. N.: An emerging global aerosol climatology from the MODIS satellite sensors, J. Geophys. Res., 113, D14S07, doi:10.1029/2007JD009661, 2008.

Ricchiazzi, P., Yang, S., Gautier, C., and Sowle, D.: SBDART: A Research and Teaching Software Tool for PlaneParallel Radiative Transfer in the Earth's Atmosphere, B. Am. Meteor. Soc., 79, 2101-2114, doi:10.1175/1520 0477(1998)079<2101:SARATS>2.0.CO;2, 1998.

Roger, J., Mallet, M., Dubuisson, P., Cachier, H., Vermote, E., Dubovik, O., and Despiau, S.: A synergetic approach for estimating the local direct aerosol forcing: Application to an urban zone during the Expérience sur Site pour Contraindre les Modeles de Pollution et de Transport d'Emission (ESCOMPTE) experiment, J. Geophys. Res. 111, d13208, doi:10.1029/2005JD006361, 2006.

Rothman, L. S., Gordon, I. E., Barbe, A., Benner, D. C., Bernath, P. F., Birk, M., Boudon, V., Brown, L. R., Campargue, A., Champion, J.-P., Chance, K., Coudert, L. H., Dana, V., Devi, V. M., Fally, S., Flaud, J.-M., Gamache, R. R., Goldman, A., Jacquemart, D., Kleiner, I., Lacome, N., Lafferty, W. J., Mandin, J.Y., Massie, S. T., Mikhailenko, S. N., Miller, C. E., MoazzenAhmadi, N., Naumenko, O. V., Nikitin, A. V., Orphal, J., Perevalov, V. I., Perrin, A., Predoi-Cross, A., Rinsland, C. P., Rotger, M., Šimečková, M., Smith, M. A. H., Sung, K., Tashkun, S. A., Tennyson, J., Toth, R. A., Vandaele, A. C., and Vander Auwera, J.: The HITRAN 2008 molecular spectroscopic database, J. Quant. Spectrosc. Radiat. Transf., 110, 533-572, 2009.

Ryder, C. L., Highwood, E. J., Lai, T. M., Sodemann, H., and Marsham, J. H.: Impact of atmospheric transport on the evolution of microphysical and optical properties of Saharan dust, Geophys. Res. Lett., 40, 2433-2438, doi:10.1002/grl.50482, 2013a.

Ryder, C. L., Highwood, E. J., Rosenberg, P. D., Trembath, J., Brooke, J. K., Bart, M., Dean, A., Crosier, J., Dorsey, J., Brindley, H., Banks, J., Marsham, J. H., McQuaid, J. B., Sodemann, H., and Washington, R.: Optical properties of Saharan dust aerosol and contribution from the coarse mode as measured during the Fennec 2011 aircraft campaign, Atmos. Chem. Phys., 13, $303-$ 325, doi:10.5194/acp-13-303-2013, 2013 b.

Saha, A., Mallet, M., Roger, J. C., Dubuisson, P., Piazzola, J., and Despiau, S.: One yearmeasurements of aerosol optical properties over an urban coastal site: Effect on local direct radiative forcing, Atmos. Res., 90, 195-202, 2008.

Sicard, M., Rocadenbosch, F., Reba, M. N. M., Comerón, A., Tomás, S., García-Vízcaino, D., Batet, O., Barrios, R., Kumar, D., and Baldasano, J. M.: Seasonal variability of aerosol optical properties observed by means of a Raman lidar at an EARLINET site over Northeastern Spain, Atmos. Chem. Phys., 11, 175-190, doi:10.5194/acp-11-175-2011, 2011.

Sicard, M., Mallet, M., García-Vizcaíno, D., Comerón, A., Rocadenbosch, F., Dubuisson, P., and Muñoz-Porcar, C.: Intense dust and extremelly fresh biomass burning in Barcelona, Spain: characterization of their optical properties and estimation of their radiative forcing, Environ. Res. Lett., 7, 034016 , doi:10.1088/1748-9326/7/3/034016, 2012. 
Sicard, M., Bertolín, S., Mallet, M., Dubuisson, P., and Comerón, A.: Estimation of a radiative transfer model in the longwave spectral range: sensitivity study and application to real cases, Proc. SPIE Remote Sens., 8890, doi:11.17/12.2029471, 2013.

Slingo, A., Ackerman, T. P., Allan, R. P., Kassianov, E. I., McFarlane, S. A., Robinson, G. J., Barnard, J. C., Miller, M. A., Harries, J. E., Russell, J. E., and Dewitte, S.: Observations of the impact of a major Saharan dust storm on the atmospheric radiation balance, Geophys. Res. Lett. 33, L24817, doi:10.1029/2006GL027869, 2006.

Sokolik, I. and Golitsyn, G.: Investigation of optical and radiative properties of atmospheric dust aerosols, Atmos. Environ., 27, 2509-2517, 1993.

Sokolik, I., Andronova, A., and Johnson, T. C.: Complex refractive index of atmospheric dust aerosols, Atmos. Environ., 27, 24952502, 1993.

Sokolik, I. N., Toon, O. B., and Bergstrom, R. W.: Modeling the radiative characteristics of airborne mineral aerosols at infrared wavelengths, J. Geophys. Res., 103, 8813-8826, 1998.

Stamnes, K., Tsay, S., Wiscombe, W., and Jayaweera, K.: Numerically stable algorithm for discrete-ordinate-method radiative transfer in multiple scattering and emitting layered media, Appl. Optics, 27, 2502-2509, 1988.

Tanré, D., Bréon, F. M., Deuzé, J. L., Dubovik, O., Ducos, F., François, P., Goloub, P., Herman, M., Lifermann, A., and Waquet, F.: Remote sensing of aerosols by using polarized, directionnal and spectral measurements within the A-Train: the PARASOL mission", Atmos. Meas. Tech., 4, 1383-1395, doi:10.5194/amt-4-1383-1395-2011, 2011.

Valenzuela, A., Olmo, F. J., Lyamani, H., Antón, M., Quirantes, A., and Alados-Arboledas, L.: Classification of aerosol radiative properties during African desert dust intrusions over southeastern Spain by sector origins and cluster analysis, J. Geophys. Res. 117, D06214, doi:10.1029/2011JD016885, 2012.

Vogelmann, A., Flatau, P., Szczodrak, M., Markowicz, K., and Minnett, P.: Observations of large aerosol infrared forcing at the surface, Geophys. Res. Lett., 30, 1655, doi:10.1029/2002GL016829, 2003.

Volz, F.: Infrared Refractive Index of Atmospheric Aerosol Substances, Appl. Optics, 11, 755-759, 1972.

Volz, F.: Infrared optical constant of ammonium sulfate, Sahara dust, volcanic pumice, and flash, Appl. Optics 12, 3, 564-568, 1973.

Volz, F.: Infrared optical constants of aerosols at some locations, Appl. Optics, 22, 23, 3690-3700, 1983.
Wagner, F., Bortoli, D., Pereira, S., Costa, M. J., Silva, A. M., Weinzierl, B., Esselborn, M., Petzold, A., RASP, K., Heinhold, B., and Tegen, I.: Properties of dust aerosol particles transported to Portugal from the Sahara desert, Tellus 61B, 297-306, 2009.

Wang, K., Wan, Z., Wang, P., Sparrow, M., Liu, J., Zhou, X., and Haginoya, S.: Estimation of surface longwave radiation and broadband emissivity using Moderate Resolution Imaging Spectroradiometer (MODIS) land surface temperature/emissivity products, J. Geophys. Res. 110, D11109, doi:10.1029/2004JD005566, 2005.

Weinzierl, B., Sauer, D., Esselborn, M., Petzold, A., Veira, A., Rose, M., Mund, S., Wirth, M., Ansmann, A., Tesche, M., Gross, S., and Freudenthaler, V.: Microphysical and optical properties of dust and tropical biomass burning aerosol layers in the Cape Verde region-an overview of the airborne in situ and lidar measurements during SAMUM-2, Tellus B, 63, 589-618, doi:10.1111/j.1600-0889.2011.00566.x, 2011.

Yang, P., Feng, Q., Hong, G., Kattawar, G. W., Wiscombe, W. J., Mishchenko, M. I., Dubovik, O., Laszlo, I., and Sokolik, I. N.: Modeling of the scattering and radiative properties of nonspherical dust-like aerosols, Aerosol Sci. 38, 995-1014, 2007.

Yoshioka, M., Mahowald, N., Conley, A. J., Collins, W. D., Fillmore, D. W., Zender, C. S., and Coleman, D. B.: Impact of desert dust radiative forcing on Sahel precipitation: relative importance of dust compared to sea surface temperature variations, vegetation changes and greenhouse gas warming, J. Climate 16, 14451467, doi:10.1175/JCLI4056.1, 2007.

Yu, H., Kaufman, Y. J., Chin, M., Feingold, G., Remer, L. A., Anderson, T. L., Balkanski, Y., Bellouin, N., Boucher, O., Christopher, S., DeCola, P., Kahn, R., Koch, D., Loeb, N., Reddy, M. S., Schulz, M., Takemura, T., and Zhou, M.: A review of measurement-based assessments of the aerosol direct radiative effect and forcing, Atmos. Chem. Phys., 6, 613-666, doi:10.5194/acp-6-613-2006, 2006.

Zhang, J. and Christopher, S. A.: Longwave radiative forcing of Saharan dust aerosols estimated from MODIS, MISR, and CERES observations on Terra, Geophys. Res. Lett. 30, 2188, doi:10.1029/2003GL018479, 2003.

Zhao, C., Liu, X., Ruby Leung, L., and Hagos, S.: Radiative impact of mineral dust on monsoon precipitation variability over West Africa, Atmos. Chem. Phys., 11, 1879-1893, doi:10.5194/acp11-1879-2011, 2011. 